LA-14038

Approved for public release;

distribution is unlimited.

\title{
94-1 R\&D Program Annual Operating Plan
}

Fiscal Year 2003

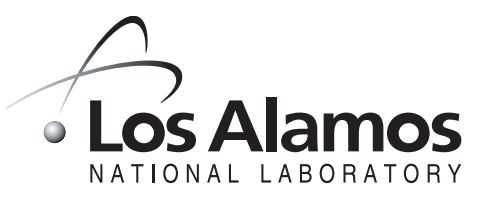


Los Alamos National Laboratory, an affirmative action/equal opportunity employer, is operated by the University of California for the United States Department of Energy under contract W-7405-ENG-36.

This report was prepared as an account of work sponsored by an agency of the United States Government. Neither the Regents of the University of California, the United States Government nor any agency thereof, nor any of their employees make any warranty, express or implied, or assume any legal liability or responsibility for the accuracy, completeness, or usefulness of any information, apparatus, product, or process disclosed, or represent that its use would not infringe privately owned rights. Reference herein to any specific commercial product, process, or service by trade name, trademark, manufacturer, or otherwise does not necessarily constitute or imply its endorsement, recommendation, or favoring by the Regents of the University of California, the United States Government, or any agency thereof. The views and opinions of authors expressed herein do not necessarily state or reflect those of the Regents of the University of California, the United States Government, or any agency thereof. Los Alamos National Laboratory strongly supports academic freedom and a researcher's right to publish; as an institution, however, the Laboratory does not endorse the viewpoint of a publication or guarantee its technical correctness. 
LA-14038

Issued: September 2003

\title{
94-1 R\&D Program Annual Operating Plan
}

Fiscal Year 2003

\author{
Richard E. Mason \\ Pamela D. Dominguez
}

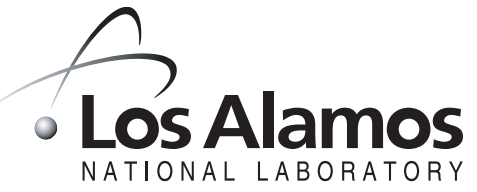





\title{
94-1 R\&D Program Annual Operating Plan Fiscal Year 2003
}

\author{
Compiled by \\ Pam D. Dominguez \\ Richard E. Mason
}

\section{Executive Summary}

The 94-1 R\&D Program focuses on developing the technical basis for stabilizing and safely storing plutoniumbearing materials. To address these issues, we have in place a material identification and stabilization project, a surveillance and monitoring project, and a management team. 


\section{Contents}

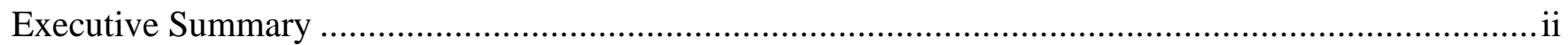

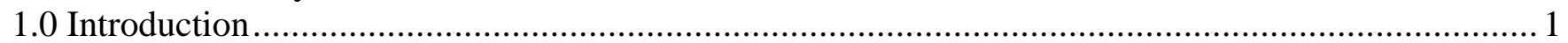

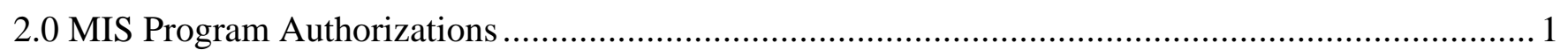

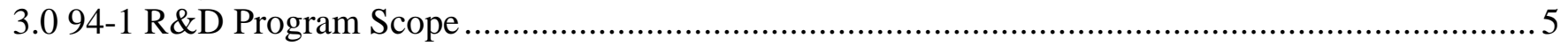

3.1 Materials Identification \& Stabilization Technologies Project ............................................. 7

3.1.1 Pu Materials Characterization and Handling Task .......................................................... 9

3.1.3 MIS Inventory and Database Maintenance Task .......................................................... 12

3.1.4 Implementation of NDA Analysis Methods Task ....................................................... 13

3.1.5 Stabilization and Packaging Support Task ......................................................... 15

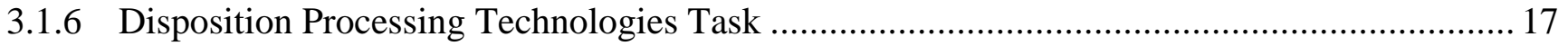

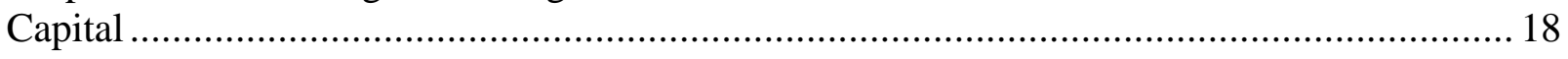

3.2 Surveillance \& Monitoring Technology Project ............................................................. 19

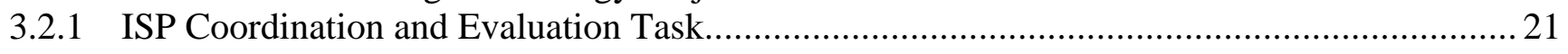

3.2.2 Container Performance Task............................................................................ 23

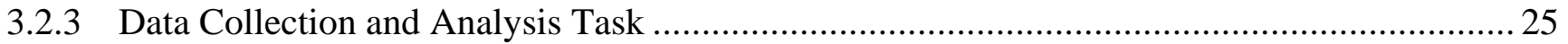

3.2.4 Shelf-Life Studies ............................................................................................. 28

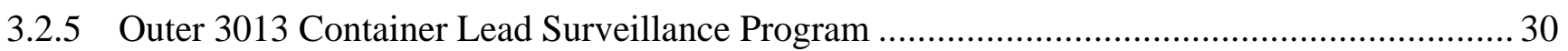

3.2.6 Container Pressure Measurements Task .............................................................. 32

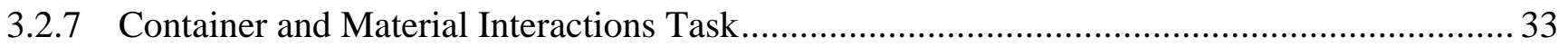

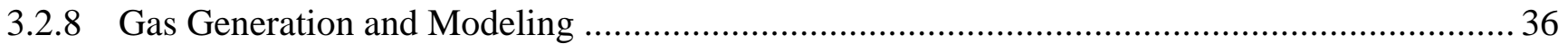

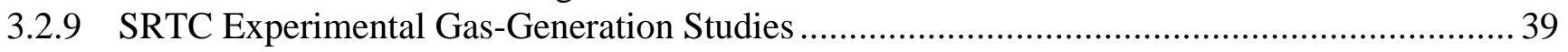

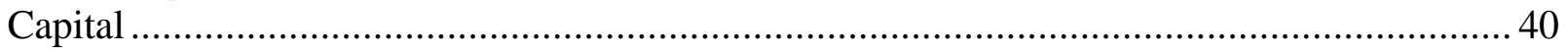

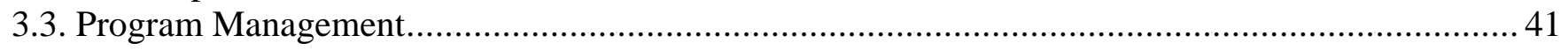

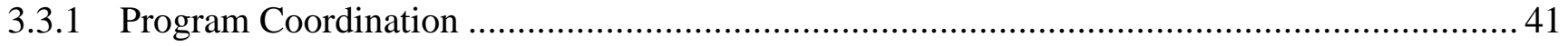

3.3.2 3013 Standard Maintenance ............................................................................... 43

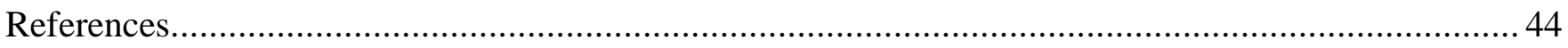

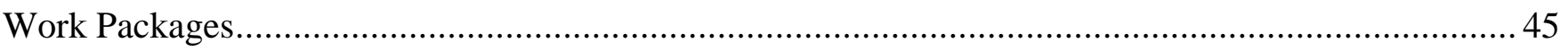

Task Name: Pu Materials Characterization and Handling ................................................... 1

Task Name: MIS Inventory and Database Maintenance.................................................. 4

Task Name: Implementation of NDA Analysis Methods ....................................................... 7

Task Name: Stabilization and Packaging Support............................................................ 11

Task Name: ISP Program Coordination \& Evaluation .................................................. 14

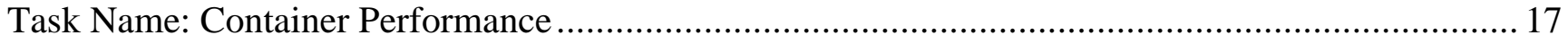

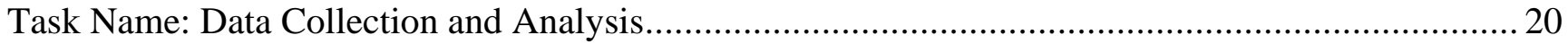

Task Name: Shelf Life Studies: Large and Small Scale ........................................................ 24

Task Name: Outer 3013 Container Lead Surveillance Program ................................................ 28

Task Name: Container and Material Interactions ............................................................. 30

Task Name: Electron Microscopy of Container Corrosion...................................................... 33

Task Name: Modeling of Gas Generation on Actinide Surfaces ............................................... 35

Task Name: SRTC Experimental Gas Generation Studies ...................................................... 39

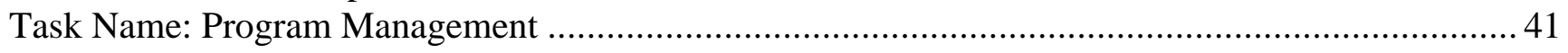




\subsection{Introduction}

The Laboratory's 94-1 R\&D Program is conducted in response to (1) the Defense Nuclear Facilities Safety Board (DNFSB) Recommendation 94-1, 2000-1, and (2) the DNFSB letter to T. J. Glauthier of December 6, 1999, which emphasizes that material stored in a 3013 container must be represented in the Laboratory's Materials Identification and Surveillance (MIS) program. Implementation of the 94-1 R\&D Program is the responsibility of the Office of Integration and Disposition. Our program focuses on accelerating the Department of Energy's (DOE's) efforts to reduce health and safety risks to workers, the public, and the environment. Coordinating with the Albuquerque Nuclear Materials Stewardship Office, the Office of Integration of Deposition continues to direct activities under this project that involve the development of stabilization technologies.

This program also maintains the viability of the 3013 standard, Section 6, which requires that materials are represented in the MIS inventory.

\subsection{MIS Program Authorizations}

On May 26, 1994, the DNFSB issued Recommendation 94-1, which expressed the board's concern regarding nuclear materials left in the manufacturing "pipeline" after the United States had stopped producing nuclear weapons. The DNFSB emphasized the need to remediate these materials. After establishing the Nuclear Materials Stabilization Task Group, DOE issued an implementation plan to address these concerns ("Defense Nuclear Facilities Safety Board Recommendation 94-1 Implementation Plan," February 28, 1995).

Under the MIS Program, Recommendation 94-1, Sub-recommendation (2), states the following: ". . . a research program [should] be established to fill any gaps in the information base needed for choosing among the alternate processes to be used in safe interim conversion of various types of fissile materials to optimal forms for safe interim storage and the longer term disposition. Development of this research program should be addressed in the program plan called for by [the Board]."

In response to the Implementation Plan for the Remediation of Nuclear Materials in the Defense Nuclear Facilities Complex (Revision 2) (January 27, 2000) Appendix G Summary of 94-1 Research and Development Program, our program will

- continue to develop surveillance and monitoring techniques for long-term vault storage of special nuclear materials (SNM). Included in this effort are materials identification and surveillance activities, as well as the development of novel surveillance and monitoring technologies to support a long-term integrated surveillance program at storage sites.

- maintain core technology (i.e., technical expertise for SNM). Current areas include materials science, gas-solid chemistry, separation science, surface science, smart materials, and chemical thermodynamics. 
As required by the Implementation Plan for Stabilization and Storage of Nuclear Materials - the Department of Energy Plan in Response to DNFSB Recommendations 2000-1 Revision 2 Appendix G (July 2002), the 94-1 R\&D Program conducts the following activities:

- Participates in Environmental Management (EM) site closure initiatives and adheres to requirements outlined in DOE-STD-3013. Building upon the successes of previous years, we continue to provide significant support to (1) closing EM sites and (2) ensuring that 3013 materials remain safe and secure until their final deposition.

- Assists closure sites by providing necessary technology and technical support to meet closure schedules. To meet such schedules, we provide the technical basis for riskbased prioritization, stabilization-process development, and packaging requirements for safe shipments. The current work scope consists of the following: (1) resolve the moisture-measurement issue, (2) quantify specific stabilization processes, (3) continue to refine the DOE-STD-3013 technical basis, and (4) validate a gas-generation model for pure oxides. To examine process parameters for process quantification, we will use both laboratory studies and engineering analyses for unexpected failures.

- Helps develop storage standards. As part of this activity, we conduct accelerated shelflife studies to detect incipient failure mechanisms. We also are developing a complexwide surveillance philosophy, program, and implementation plan, all of which provide a cost-effective and integrated program that consolidates information at one central location.

- Works to improve the technical understanding of the stabilization process and material behavior during storage. With such knowledge, we can provide technically defensible information, which in turn will enable us to support the safe, long-term storage of stabilized materials in approved packages. It also ensures that technical capabilities will be available in the future to address unforeseen problems. We are presently working on plutonium-bearing materials that must be stabilized, packaged, and stored in accordance with DOE-STD-3013.

- Resolves technical issues that ensure with high confidence that all 3013 materials are safely stabilized, packaged, and stored for up to 50 years pending ultimate disposition. Future efforts and related milestones depend upon packaging schedules and closure dates of the 3013 sites; such efforts are also ultimately dependent upon the final disposition of the last item. As required, the 94-1 R\&D Program will continue to support sites that are stabilizing and packaging materials. To ensure safe storage of materials until final disposition, we will maintain representative materials, perform shelf-life studies and surveillance activities, and maintain the Core Technology Program.

- Continue to conduct an integrated surveillance program of 3013 containers. This program includes (1) conducting destructive and nondestructive evaluation of 3013 containers, (2) performing chemical analysis of stored materials, (3) maintaining a database, and (4) analyzing baseline and surveillance data as they are collected. Shelf-life experiments will help identify potential failure mechanisms and help identify critical material types that in turn will help us focus on surveillance activities.

- Support other sites. Once the Rocky Flats Environmental Technology Site (RFETS) is closed, it is anticipated that our program will support the closure of the Hanford site, as well as support the reduction of excess plutonium inventory at other sites, such as the 
Savannah River Site (SRS), Los Alamos National Laboratory, and Lawrence Livermore National Laboratory.

In the near term (as described above), the 94-1 R\&D Program continues to support the stabilization and packaging sites through a variety of activities, including process qualification and material identification. Once RFETS and the Hanford Site near closure and their 3013 material is in storage, the 94-1 R\&D Program will shift its focus to long-term surveillance and storage issues.

For materials characterization, the 94-1 R\&D Program adheres to the following guidance:

- DOE-STD-3013-2000 section 6.6 Quality Assurance-Quality assurance to meet 10 CFR 830.120 shall be performed in accordance with site Quality Assurance Plans. In accordance with this plan, the sites must ensure that oxides packaged to this standard are represented by items accumulated in the MIS.

- To satisfy section 6.6, an MIS program must be maintained.

- The DNFSB letter to Mr. Glauthier (dated December 6, 1999) accepts the DOE-STD3013-99 standard: "The revised standard specifies that only materials that are represented in the Los Alamos National Laboratory Materials Identification and Surveillance Program may be packaged for long-term storage. The Board believes that this requirement will play an important role in ensuring that the standard does not allow packaging of materials that could result in unsafe conditions during storage."

With respect to the Integrated Surveillance Program (ISP), the 94-1 R\&D Program adheres to the following guidance:

- DOE-STD-3013-2000 section 6.4.1. Surveillance Program. Based on this guidance, the 94-1 R\&D Program's surveillance programs address site-specific operating conditions and approaches that maintain quality assurance.

- EM-21 memorandum to distribution from John Tseng and Thomas Kiess, July 11, 2001: "By this memorandum, both the Office of Defense Programs (DP) and the Office of Environmental Management (EM) agree to establish an Integrated Surveillance Program (ISP) for stabilization and packaging of plutonium-bearing materials for long-term storage."

- On December 2, 2002, the U.S. President signed Congressional bill H. R. 4546 House of Representatives, 107th Congress, 2d Session, Report 107-772 National Defense Authorization Act for Fiscal Year 2003 Conference Report to Accompany H. R. 4546 November 12, 2002. 4546. In part it states the following:

(k) DEFENSE NUCLEAR FACILITIES SAFETY BOARD STUDY-

(1) The Defense Nuclear Facilities Safety Board shall conduct a study of the adequacy of the K-Area Materials Storage facility (KAMS) at the Savannah River Site for storage of defense plutonium and defense plutonium materials in connection with the disposition program provided in this section and in the Department of Energy's amended Record of Decision for fissile materials disposition. Not later than one year after the date of the enactment of this Act, the 
Defense Nuclear Facilities Safety Board shall submit to Congress and the Secretary of Energy a report on the study. The report shall--

(A) at a minimum, address--

(i) the suitability of KAMS and related support facilities for monitoring and observing any such plutonium and plutonium materials stored in KAMS;

(ii) the adequacy of the provisions the Department has made for remote monitoring of such plutonium and plutonium materials by way of sensors and for handling of retrieval of such plutonium and plutonium materials; and

(iii) the adequacy of KAMS should such plutonium and plutonium materials continue to be stored there beyond 2019; and

(B) contain such recommendations, as the Board considers necessary or desirable to enhance the safety, reliability, and functionality of KAMS.

(2) Not later than six months after the date on which the report under paragraph (1) is submitted to Congress, and every one-year thereafter, the Secretary and the Board shall each submit to Congress a report on the Secretary's action with respect to the recommendations.

The 94-1 R\&D Program applies the following guidance in maintaining its ISP database:

- Based upon guidance in DOE-STD-3013-2000 section 6.5.1 Data Base, the 94-1 R\&D Program maintains an electronic database that serves as a source of relevant information about stored materials and packages. This database consists of several files (which, in themselves, may be databases), some of which are classified. For completeness, the databases are coordinated and generally compatible with the MC\&A databases.

- The following guidance is taken from DOE-STD-3013-2000 section 6.4.3 Evaluation of Surveillance Data:

1. Surveillance data from an inspection shall be compared against baseline measurements to identify any changes.

2. If at any time an unexpected change in a Package is noted, an evaluation shall be performed and corrective action taken as appropriate. This evaluation shall include, as appropriate, (1) options for opening the Package, (2) consideration for inspecting other similar Packages, based on factors such as contents, origin, and date of closure, and (3) assessment of potential consequences.

The following points provide technical justification for the 94-1 R\&D Program:

- Measuring moisture on actinides that have accompanying impurities is not well established.

- Sub-sampling could be minimized if the Neutron Moderation Instrument (NMI) was operational, but the NMI and its technical basis are not yet established.

- We have no long-term data (more than a few years) regarding the storage of actinides in hermetically sealed containers (food-pack cans deform, thereby leaking before or after 10 psi). 
- Personnel often characterize materials inside containers by using "process knowledge." The problems with this approach are that (1) the exact contents are not usually known and (2) the process knowledge may be incomplete or wrong.

- We must address issues associated with the pressure that builds up in these containers because they are hermetically sealed. Food-pack cans tend to leak before or after attaining pressures of $10 \mathrm{psi}$.

- Chloride salts can corrode stainless steel. Therefore, we must verify that low-moisture content is sufficient to impede salt corrosion in stainless-steel containers.

- Because our effort consists of a new packaging system, we must demonstrate that it is safe, particularly when a container can hold as much as $5 \mathrm{~kg}$ of actinide oxides.

This is the first time that we have prepared the 94-1 R\&D Program in an Annual Operating Plan (AOP) format. We have designed this document so that we can regularly update it throughout the year, and as a result it will accurately reflect ongoing $R \& D$ activities that support stabilization projects. Table 1 identifies the budget and the first- through third-level WBS (work breakdown structure) tasks. Figure 1 shows the first- and second-level WBS of the 94-1 R\&D Program. Also included in this document are the Laboratory work packages and a detailed schedule.

\subsection{4-1 R\&D Program Scope}

The 94-1 R\&D Program is an integrated program between the DOE Environmental Management Program Office and the National Nuclear Security Administration Defense and Nonproliferation Program Offices. Directing the program is the Office of Integration and Disposition, which works through the DOE-AL Nuclear Material Stewardship Project Office (NMSPO). NMSPO has established Los Alamos National Laboratory as the lead laboratory to implement the 94-1 R\&D Program.

Although the majority of research is conducted at the Laboratory, work is contracted to universities, other laboratories, and other DOE facilities as appropriate. The program has the following objectives:

- Ensure that closure and storage sites have the necessary technology and technical support to meet closure schedules.

- Address long-term storage issues.

- Provide technically defensible information to support the safe and long-term storage of stabilized materials in approved packages.

Specifically, this program ensures that 94-1 materials and containers are safe and secure until final disposition by addressing (1) issues related to stabilization and packaging of 94-1 materials and (2) conducting surveillance of materials and storage containers. 


\section{Table 1: FY03 Budget at a \$9,400,000 funding level}

$\begin{array}{cc}301 \mathrm{~A} & \\ 1.1 & \mathrm{M} 66 \mathrm{D} / 1100 \\ 1.1 .1 & \mathrm{M} 66 \mathrm{D} / 1110 \\ 1.1 .2 & \mathrm{M} 66 \mathrm{D} / 1120 \\ 1.1 .3 & \mathrm{M} 66 \mathrm{D} / 1130 \\ 1.1 .4 & \mathrm{M} 66 \mathrm{D} / 1140 \\ 1.1 .5 & \mathrm{M} 66 \mathrm{D} / 1150 \\ 1.1 .6 & \mathrm{M} 66 \mathrm{D} / 1160\end{array}$

$301 \mathrm{C}$

1.2

1.2.1 M66E/1210

1.2.2 M66E/1220

1.2.3 M66E/1230

1.2.4 M66E/1240

1.2.5 M66E/1250

1.2.6 M66E/1260

1.2.7 M66E/1270

1.2.8 M66E/1280

\section{Materials Identification \& Stabilization Technologies}

$$
\text { Bender }
$$

Dworzak

Watts/Bender

Hollis/Morales

Dworzak

Dworzak

Pu Materials Characterization and Handling

Shipping/Receiving/Packaging

MIS Inventory and Database Maintenance

Implementation of NDA Analysis Methods

Stabilization and Packaging Support

Disposition Processing Technologies

CAPITAL

TOTAL MIST
$\$ 70$

$\$ 1,200$

$\$ 0$

$\$ 252$

$\$ 925$

$\$ 499$

$\$ 0$

$\$ 290$

$\$ 3,236$

$\$ 120$

$\$ 881$

$\$ 523$

$\$ 820$

$\$ 1,669$

$\$ 300$

Funded in FY02

$\$ 758$

$\$ 225$

$\$ 400$

$\$ 50$

$\$ 5,345$

$301 \mathrm{E}$

$1.3 \mathrm{M} 66 \mathrm{~F} / 1300$

Program Management

$\$ 25$

Mason Program Coordination

$\$ 1,177$

1.3.1 M66F/1310

Vacant

3013 Standard Maintenance

TOTAL Program Management

$\$ 1,202$

TOTAL Program

Expected funds to meet the $\$ 9,864$ budget include $\$ 9,400 \mathrm{DOE} / \mathrm{AL}$ allocation, $\$ 306 \mathrm{k}$ equipment, and $\$ 158 \mathrm{k}$ in FY02 carryover.

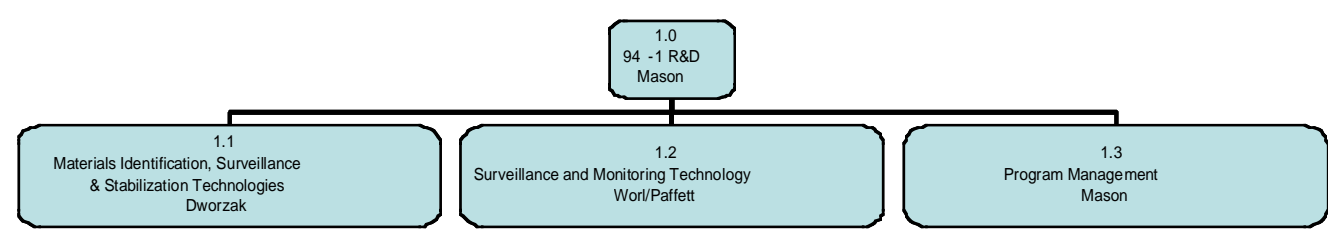

Figure 1: First and second level WBS of the 94-1 R\&D program 


\subsection{Materials Identification \& Stabilization Technologies Project \\ Project Leader: Dworzak}

As outlined in the FY03 program plan, this project consists of the following tasks:

- Provide, as requested, technical support for immobilization activities that involve nonweapons-grade plutonium.

- Perform prompt-gamma studies, thus expanding the capability to measure impurities in packaged materials at Los Alamos and Hanford.

- Deploy prompt-gamma capability to HF and SRS.

- Develop technical basis and obtain analytical data to stabilize and store impure materials in 3013 containers. Concentrate on materials with only 30 to 50\% plutonium.

- Evaluate new and anomalous (anomalous re-adsorption and chemistry results) materials to support representation in MIS inventory.

- Provide technical support in shipping food-pack cans from from RFETS, SRS, and Hanford to Los Alamos for representation in MIS Program.

- Design a device that punctures food-pack cans and obtain samples of headspace gases from Hanford and RFETS cans sent for MIS analysis (FY02). Receive food-pack containers from the DOE Complex and sample headspace gases (FY03). The device should be operational in a glovebox in FY03-04.

- Identify actinide materials that require stabilization, packaging, and storage (this task does not include development of standards).

- Maintain inventory and database for material identification and surveillance.

- Provide experimental data and technical expertise to establish criteria-specific stabilization processes to all sites that intend to apply process quantifications with an emphasis on hard-to-process items.

- Develop (FY02) and demonstrate (FY03) neutron moderation to measure moisture content in sealed 3013 containers at Los Alamos and Hanford.

- Develop and implement a test plan to validate process-qualification requirements.

Figure 2 shows tasks activities and responsible parties for each one. 


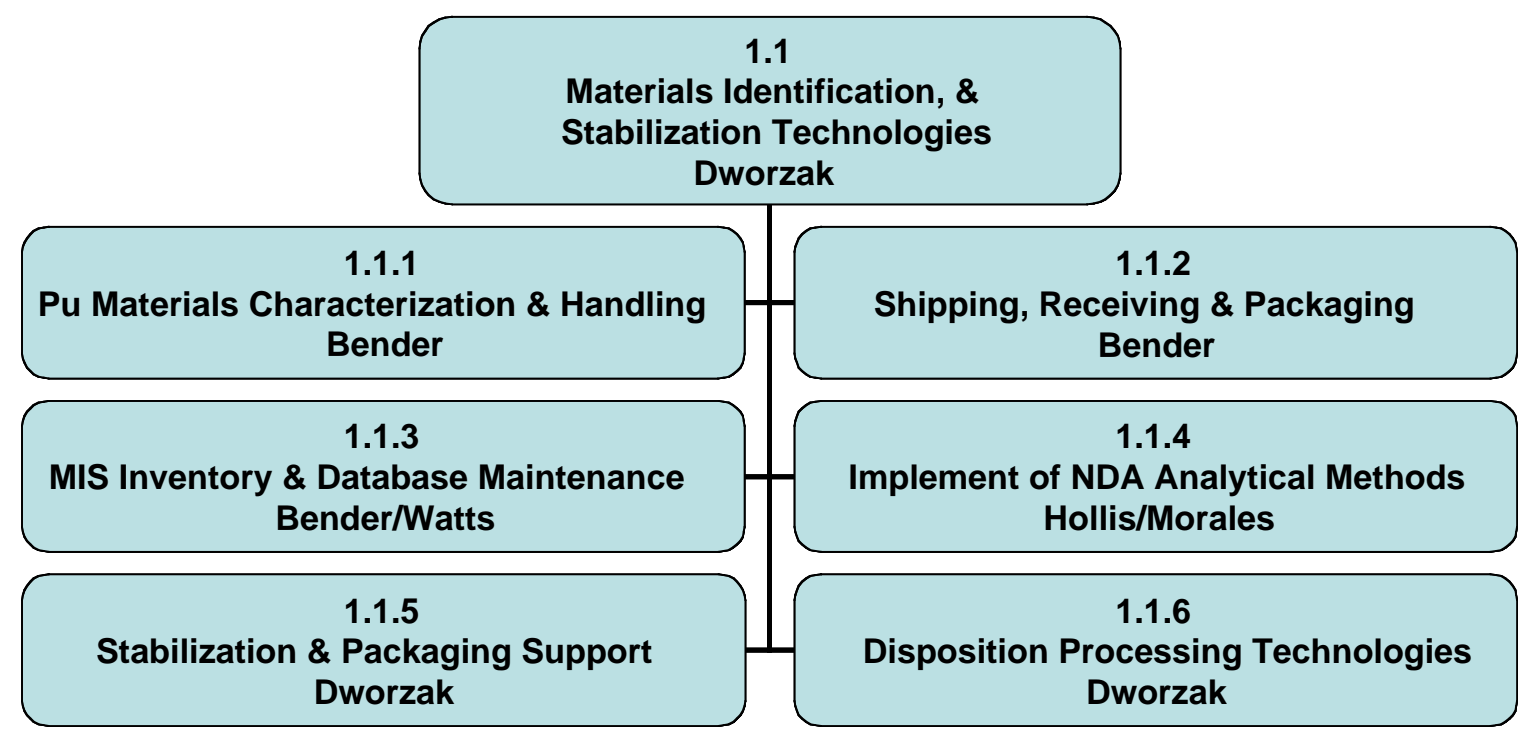

Figure 2: Activities in WBS 1.1 


\subsubsection{Pu Materials Characterization and Handling Task \\ Principal Investigator: Bender}

Scope

The Pu Materials Characterization and Handling task is the keystone operation for any activity that uses SNM. The objectives of this task are to

- receive items from different sites,

- demonstrate adequate stabilization of plutonium-bearing materials,

- characterize materials (physical and chemical characterization) from the sites and add the results to the MIS inventory after passing the evaluation,

- maintain the MIS inventory, and

- provide SNM to experimenters working on other tasks and activities of the 94-1 R\&D Program.

\section{Issues}

- Processing and safe storage ultimately depend upon the packaged material.

- Many stabilization and packaging sites no longer have the analytical capabilities to characterize unusual or problem materials. Consequently, these materials must be sent to Los Alamos, where such capabilities still exist.

- Personnel must maintain the MIS inventory until all representative stored material is processed and is no longer in the EM inventory.

- These materials need to be on hand for future evaluations, particularly if there are problems with stability or storage.

- We must determine and evaluate the physical and chemical characteristics of items within the DOE Complex that may influence processing, equipment performance, and safe storage.

- Synergistic combinations of different materials may cause or enhance corrosion or gas generation.

Activities for FY03 consist of the following:

\section{Approach}

- Identify materials that will be stabilized, packaged, and stored with actinides.

- Develop technical basis and collect analytical data to stabilize and store impure actinides in 3013 containers. Focus on materials that have actinides with impurity contents greater than $50 \%$.

- Evaluate new and anomalous (anomalous re-adsorption and chemistry results) materials to support representation in MIS inventory.

- Receive food-pack containers from the DOE Complex and from these take samples of headspace gases.

- Maintain materials in the MIS inventory.

- Support the development of a TGA instrument by providing characterization data and SNM samples.

- Support the development of an NMI by providing characterization data and SNM samples. 
- Support the shelf-life task by providing characterization data and SNM samples.

- Support the development of prompt-gamma analysis by providing characterization data and SNM samples.

- Clean out glovebox in room 212 and prepare said glovebox to process MIS materials.

- Resolve Si analytical differences between Hanford, RFETS, and the Laboratory.

The following table lists activities that are identified as issues but are not funded.

$\underline{\text { Issue or activity not funded }}$

Only 30 chemistry samples are funded. We anticipate 90 required samples, which would cost an additional $\$ 540 \mathrm{k}$.

By purchasing and installing an X-ray diffraction machine, we can identify crystalline compounds in MIS materials.

\section{Additional funds needed}

\$540K

See Capital

\section{Deliverables}

\begin{tabular}{c|l|l} 
Date & Description & \multicolumn{2}{l}{ PI } \\
\hline $1 / 30 / 03$ & Issue white paper "Potential Effects of Plutonium Oxide Impurity & Dworzak \\
& Compounds on Process and Containers for Long-Term Storage" & \\
$4 / 30 / 03$ & Issue item re-evaluation report & Bender \\
$5 / 15 / 03$ & $\begin{array}{l}\text { Complete characterization and issue report on the two Hanford } \\
\text { items received in FY02 }\end{array}$ & Bender \\
$9 / 30 / 03$ & $\begin{array}{l}\text { Issue a year-end report } \\
\text { Bender }\end{array}$
\end{tabular}




\subsubsection{Pu Shipping/Receiving/Packaging}

Principal Investigator: Not assigned (no funding allocated to this task)

\section{Scope}

The Pu Shipping/Receiving/Packaging task supports the 94-1 R\&D Program by (1) receiving items from DOE Complex sites and (2) packaging the materials and returning them to the sites.

\section{Issues}

- As of August 26, 2002, the DOE Complex cannot ship or receive uncalcined material.

- DOE sites send materials to Los Alamos so that researchers can evaluate material boundaries and storage conditions.

\section{Approach}

There are no planned activities for FY03. Future activities include

- processing $25 \mathrm{~kg}$ of material in FY04 at a cost of $\$ 500,000$.

- processing $10 \mathrm{~kg}$ of material in FY05 and beyond at a cost of $\$ 250,000 / \mathrm{yr}$.

- closing out processing of $25-39 \mathrm{~kg}$ at a cost of $\$ 600,000$.

The following table lists activities that are identified as issues but are not funded.

$\underline{\text { Issue or activity not funded }}$

The cost to recover plutonium or send materials to SRS.

The cost to receive items from the sites are not covered.
Additional funds needed

$\$ 1,500,000$

$\$ 54,000$

\section{Deliverables}

\begin{tabular}{l|l|l} 
Date & Description & PI \\
\hline $10 / 30 / 02$ & $\begin{array}{l}\text { Complete direct-shipment-options report (Funded in 1.2.1 } \\
\text { and 1.3.1) }\end{array}$ & Stone/Psaras/Crooks \\
10/30/02 & Complete process/disposition agreement with the Laboratory & Mason
\end{tabular}




\subsubsection{MIS Inventory and Database Maintenance Task \\ Principal Investigators: Bender and Watts}

\section{Scope}

Task components include (1) supporting the maintenance of the MIS database, (2) updating the Web site with information recently collected or generated from ongoing studies, (3) evaluating the collected data for consistency and accuracy, and (4) maintaining MIS materials for future use in the 94-1 R\&D Program.

\section{Issues}

- Identified process or storage issues often require quick solutions. Therefore, represented materials must be available to evaluate identified issues so that time is not unduly lost in transporting the material to the laboratory.

- We must continue to update and maintain the data books and the database that enable MIS-WG members to access up-to-date data. If incoming data are not properly filed and loaded into the database, then such data are not accessible to the MIS-WG.

- Some material was loaded into the MIS database to meet site timetables. We need to verify such data for accuracy.

- We must maintain the database to ensure that it continues to benefit engineers working in the DOE Complex.

\section{Approach}

Activities for FY03 consist of the following:

- Update data as new analyses or processing steps are completed.

- Review all published data and then verify it.

- Improve the readability of the database and Web site.

- Maintain the publications list.

- Use MASS data to validate process flow charts.

The following table lists activities that are identified as issues but are not funded.

\section{Issue or activity not funded}

Data collection and evaluation are funded at 0.5 FTE each. A full FTE is required to adequately update and maintain the data books and the database.

\section{Additional funds needed}

$\$ 80 \mathrm{~K}$

\section{Deliverables}

\begin{tabular}{l|l|l} 
Date & Description & PI \\
\hline $8 / 30 / 03$ & Issue CD of Web site as an LA-UR report & Watts \\
$8 / 30 / 03$ & Issue MIS item-characterization report & Bender
\end{tabular}




\subsubsection{Implementation of NDA Analysis Methods Task \\ Principal Investigators: Hollis, Morales, and Foster}

\section{Scope}

NDA (nondestructive analysis) plays a crucial role in a site's stabilization and packaging of plutonium-bearing materials. This task's objectives are to provide the DOE Complex with analytical tools that can measure a container's moisture, composition, and condition.

\section{Issues}

- TGA-MS (trace gas analysis-mass spectroscopy) and TGA-FITR (trace gas analysisFourier transform infrared spectroscopy) are new instruments designed for moisture measurement. Therefore, we have not yet demonstrated the robustness of these instruments.

- We have evaluated only a portion of MIS-inventory materials with the help of TGA-MS and TGA-FTIR.

- We must evaluate a broader range of materials to ensure that no problems exist with such analytical methods.

- Although we anticipate no analysis problems, we do foresee difficulties with equipment maintenance when pressing impure materials.

- Because prompt-gamma analysis is a new chemical-analysis method, we have not fully demonstrated the instrument's accuracy and precision.

- Each site has its own version of X-ray radiography equipment. As a result, measurements of a container's lid are different. Such deviation of measurements affects the accuracy of calculations that determine the pressure within a container.

\section{Approach}

We will conduct the following activities during FY03:

- Evaluate impure MIS materials with TGA-MS and TGA-FTIR instruments.

- Support process-qualification applications with TGA-MS and TGA-FTIR analyses.

- Support RFETS closure activities with TGA-MS and TGA-FTIR analyses.

- Validate NMI operation by testing the instrument at Los Alamos and Hanford.

- Support Hanford processing activities with TGA-MS and TGA-FTIR analyses.

- Support SFE application at Los Alamos.

- Deploy NMI instruments at RFETS, SRS, and Los Alamos.

- Perform prompt-gamma studies that will expand our capabilities in measuring impurities in packaged materials at RFETS, Hanford, SRS, Lawrence Livermore National Laboratory, and Los Alamos.

- Deploy prompt-gamma capability to Hanford and SRS.

- Develop NDA instruments that continue to meet the ever-changing needs of processing and storage sites.

- Use chemical analyses and prompt-gamma findings to create a standard for prompt gamma.

The following table lists activities that are identified as issues but are not funded. 
Issue or activity not funded

A third instrument is partially built. It was being built for use at SRS or Rocky Flats.

XRD unit to measure compounds in MIS materials.
Additional funds needed

$\$ 150 \mathrm{~K}$

See Capital

\section{Deliverables}

Date Description $\quad$ PI

\begin{tabular}{l|l|l}
$1 / 15 / 03$ & Issue NMI technical basis-rev 0 & Fos
\end{tabular}

3/15/03 Issue Rev 2 report on TGA-MS and TGA-FTIR evaluations

3/30/03 Issue Prompt gamma technical basis-rev 0

8/30/03 Issue Rev 3 report on TGA-MS and TGA-FTIR evaluations

8/30/03 Issue NMI technical basis—rev 1

8/30/03 Issue Prompt gamma technical basis—rev 1
Foster/Martin

Morales

Foster/Narlesky

Morales

Foster/Martin

Foster/Narlesky 


\title{
3.1.5 Stabilization and Packaging Support Task \\ Principal Investigator: Dworzak
}

\begin{abstract}
Scope
This task supports the expedient resolution of unforeseen issues associated with stabilization, packaging, transportation, and storage. The experiments focus on determining the moistureuptake behavior of oxides proposed for long-term storage. Our objectives are to (1) produce empirical and theoretical models that enable researchers to determine the effects of given environments on the moisture uptake by oxide batches during and after cooling and (2) relate such information to shelf-life study results and 3013 container storage. Our studies use nonradioactive surrogate materials to represent actual oxides. We use these surrogates in full-scale process equipment that has been fitted with the supplementary instrumentation and controls designed to conduct parametric testing. When practical, we will confirm results by using actual plutonium oxide batches in existing process equipment at the Los Alamos Plutonium Facility, PF-4.
\end{abstract}

\section{Issues}

- In FY02, we experienced unforeseen stabilization and storage issues related to current or past processing. We expect such issues to appear in the future.

- Engineers within the DOE Complex still do not have a complete understanding of how operational parameters control moisture pickup.

- We also do not fully understand how operational parameters affect (1) the corrosion of furnaces during stabilization or (2) corrosive materials loaded into a 3013 container.

\section{Approach}

We will conduct the following activities during FY03:

- Collaborate with university staff and students to help explore stabilization and storage issues.

- Use experimental data and technical expertise to establish stabilization-process criteria specific to all sites intending to seek process qualification. We will focus on difficult-toprocess items.

- Develop and implement a test plan to validate process qualification parameters.

- Evaluate how long a processed sample can remain exposed in a glovebox atmosphere after a moisture measurement has been conducted but before the sample is sealed in a 3013 container.

- Evaluate how salts and other known impurities during stabilization affect stabilization equipment.

- Evaluate how unanticipated constituents during stabilization affect stabilization equipment.

- Use TGA analysis to help evaluate various oxide impurities.

- Help the DOE Complex resolve stabilization and packaging issues as they occur.

- Prepare surrogate materials for SRS lead-container tests. 
The following table lists activities that are identified as issues but are not funded.

Issue or activity not funded

Additional funds needed

N/A

N/A

Deliverables

\section{Date Description}

8/30/03 Issue report on the process-parameter evaluation

$8 / 30 / 03$

$9 / 30 / 03$
Issue report on the evaluation of time/RH parameters

Issue a year-end report

Ship x-kg of surrogate material to SRS
PI

Dworzak

Dworzak

Dworzak

Gillispie/Trujillo 


\subsubsection{Disposition Processing Technologies Task \\ Principal Investigator: Dworzak}

\section{Scope}

This task supports the development of technologies that contribute to the final disposition of plutonium-bearing materials.

\section{Issues}

If any data gap, technical basis, equipment, or instrument requirement is not available during processing or storage and thus impedes disposition, it will affect storage at SRS and other sites because of established agreements with state officials and DOE obligations.

\section{Approach}

At present there are no activities for this task. However, as issues arise, we will identify appropriate tasks and deliverables.

The following table lists activities that are identified as issues but are not funded.

\section{Issue or activity not funded}

Develop n- instrument to supplement promptgamma analysis (i.e., analyze for $\mathrm{Ca}, \mathrm{S}, \mathrm{C}, \mathrm{Ni}$, etc.).

Simultaneously optimize oxide reactivity while minimizing interferences from impurity compounds for use as MOX fuel process feed.

Determine methods or processes that can eliminate unwanted constituents from oxides destined for long-term storage or MOX fuel.

Assist in optimizing stabilization and other processes for preparing material for long-term storage or MOX fuel.

\section{Additional funds needed}

\section{Deliverables}

\begin{tabular}{l|l|l} 
Date & Description & PI \\
\hline & None &
\end{tabular}




\section{Capital}

Purchased TGA for PF-4 at a cost of $\$ 290,000$. This purchase completes the construction of the can-puncture and sampling device.

The following table lists capital-equipment purchase requirements that have been identified but are not funded.

Issue or activity not funded

XRD to determine crystalline compounds in MIS materials.
Additional funds needed

$\$ 150 \mathrm{~K}$ 


\subsection{Surveillance \& Monitoring Technology Project}

Project Leaders: Worl and Paffett

This project helps storage sites meet section 6.4 .1 of the standard. Our support includes helping the sites implement surveillance programs. We coordinate these surveillance efforts with maximum effectiveness while reducing overall costs. This project takes advantage of the analytical and experimental capabilities available at SRS and Los Alamos. The general approach is as follows:

- Continue to implement the Integrated Surveillance Program and support the implementation of site-specific surveillance plans.

- Monitor sealed containers at SRS, Hanford, and Los Alamos.

- Continue to conduct shelf-life studies and evaluate materials of plutonium-bearing oxides from SRS and Los Alamos.

- Maintain database of Complex-wide packaged material.

- Review and assist Hanford with pressure-measurement devices by providing support and analysis, as well as by integrating data into the 94-1 database.

- Provide support to storage sites as necessary to resolve issues associated with the implementation of surveillance programs.

As outlined in the FY03 program plan, this project consists of the following tasks:

- Continue to implement the Integrated Surveillance Program and support the implementation of site-specific surveillance plans.

- Develop can-puncture/gas analysis device for 3013 containers.

- Modify facility/glovebox to support destructive analysis for ISP implementation.

- Receive 3013 containers for headspace-gas and destructive analyses.

- Monitor sealed containers at SRS, Hanford, and Los Alamos.

- Continue to conduct shelf-life studies and evaluate materials of plutonium-bearing oxides from SRS and Los Alamos.

- Maintain database of Complex-wide packaged material.

- Review and assist Hanford with pressure-measurement devices by providing support and analysis, as well as by integrating data into the 94-1 database.

- Provide support to storage sites as necessary to resolve issues associated with the implementation of surveillance programs.

- Develop experimental database (SRS and Los Alamos) that show gas-generation rates for well-defined materials.

- Evaluate potential gas-generation mechanisms to determine anticipated rates for problematic materials.

Figure 3 shows task activities and responsible parties for each one. 


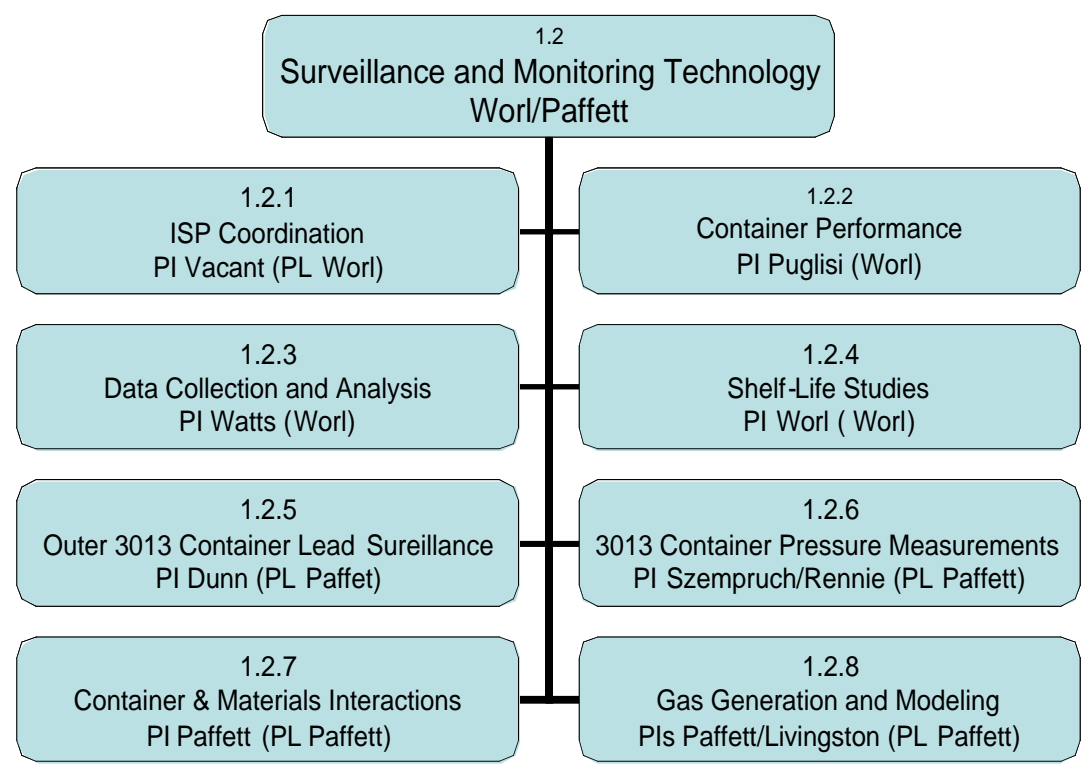

Figure 3: Activities in WBS 1.23.2.1 


\subsubsection{ISP Coordination and Evaluation Task \\ Principal Investigator: Vacant}

\section{Scope}

Surveillance activities at each site will continue to meet (1) good operation practices and (2) section 6.4 of the standard. The ISP coordination team will

- work with each site to coordinate their surveillance activities with the DOE Complex surveillance program,

- coordinate the collection of appropriate data (working with the data collection, analysis, and reporting teams), and

- evaluate available information, analyze data, and report the results to MIX WG and the ISP Steering Committee, which in turn will provide the information to the DOE Complex.

After MIS WG and ISP-SC reviews, all data and reports will be made available to the DOE Complex.

\section{Issues}

- Uncoordinated site-surveillance activities will duplicate efforts and cost more money.

- Safety issues identified at one site may not be communicated to other sites.

- Data gleaned from each site's stabilization, packaging, and storage efforts will not be available to other sites to assist and support their safe-storage efforts.

\section{Approach}

We will conduct the following activities during FY03:

- Continue to implement the Integrated Surveillance Program and support the implementation of site-specific surveillance plans.

- Work with sites on their individual site-specific surveillance plans.

- Support storage sites in their implementation of site-specific surveillance plans and resolve issues associated with implementing surveillance programs.

- Work with sites to identify, collect, and report information of value to the ISP.

- Evaluate stabilization, packaging, and surveillance data collected from RFETS, Hanford, Lawrence Livermore National Laboratory, and Los Alamos.

- Collaborate with the MIS-WG and ISP steering committee to coordinate efforts between sites. 
The following table lists activities that are identified as issues but are not funded.

Issue or activity not funded

The ISP coordinator will not be hired or identified from among Laboratory employees until the FY04 issue is resolved.

Funds are inadequate to maintain personnel who analyze, evaluate, and report promptgamma, surveillance, and site-stabilization data.

Glovebox, facility modification and approval completion.
Additional funds needed

$\$ 200 \mathrm{~K}$

$\$ 350 \mathrm{~K}$

$\$ 500 \mathrm{~K}$

\section{Deliverables}

$\begin{array}{ll}\text { Date Description } & \text { PI }\end{array}$

\begin{tabular}{l|l|l}
\hline $6 / 30 / 02$ & Identify a coordination PI & Mason \\
$7 / 30 / 03$ & $\begin{array}{l}\text { Complete annual ISP observation and recommendation report } \\
\text { and present the report to the ISP Steering Committee }\end{array}$ & Vacant \\
9/30/03 & $\begin{array}{l}\text { Issue a year-end report } \\
\text { Complete ISP Implementation Plan }\end{array}$ & \\
10/30/02 & Dworzak
\end{tabular}




\subsubsection{Container Performance Task \\ Principal Investigator: Puglisi}

\section{Scope}

This task is responsible for developing the safe-storage technical basis by evaluating real containers and materials. Our objectives are to develop and establish (1) an analysis program and (2) destructive and nondestructive examination (NDE) capabilities at Los Alamos, both of which are required for the site-wide ISP. We evaluate headspace gas composition, container condition, and material (container and stored materials). NDEs will be performed on both Los Alamos containers and containers received from other sites. We also will evaluate and apply destructive examination techniques to containers sent to Los Alamos. Results from these efforts will help researchers verify results, analyses, and safe-storage predictions from the shelf-life task, the MIS characterization task, and special topic studies.

\section{Issues}

- If a can pressurizes, we have no protocol or equipment to (1) relieve the pressure and (2) determine what gases caused the pressure in the first place.

- Containers must be opened to evaluate their long-term performance. For example, corrosion can only be evaluated by destructive examination methods.

- Some containers may hold material that requires better characterization and testing in the shelf-life program to ensure that MIS inventory and stored-material data complement expected materials and storage conditions.

\section{Approach}

We will conduct the following activities during FY03:

- Deploy a can punch designed to (1) relieve container pressure and (2) determine headspace-gas composition in any of the proposed 3013 container configurations.

- Evaluate NDE techniques and develop or suggest improvements as required.

- Develop appropriate metallographic capabilities and sampling protocols.

- Establish a protocol and obtain equipment designed to relieve pressure in 3013 containers.

Future activities include

- sampling and determining headspace gases in 3013 containers and

- establishing at SRS and Los Alamos capabilities to puncture high-pressure containers. 
The following table lists activities that are identified as issues but are not funded.

Issue or activity not funded

Pressure-chamber and container deflagration/ detonation tests to demonstrate the safety of the can-puncture system.

Revise containment hood for 3013 puncture device.

$\mathrm{AB}$ and RA evaluation support for 3013 puncture device.

Radiograph LM and LOX containers.
Additional funds needed

$\$ 200 \mathrm{~K}$

$\$ 200 K$

$\$ 100 \mathrm{~K}$

$\$ 40 \mathrm{~K}$

\section{Deliverables}

\begin{tabular}{l|l|l} 
Date & Description & \multicolumn{1}{l}{ PI } \\
\hline $8 / 30 / 02$ & Gas sample 10 Los Alamos food-pack cans & Puglisi/Bender \\
$10 / 30 / 02$ & $\begin{array}{l}\text { Develop, install, and make operational a food-pack can- } \\
\text { puncture device } \\
\text { Develop can puncture/gas analysis device for 3013 } \\
\text { containers } \\
\text { Perform facility/glovebox modification to support } \\
\text { destructive analysis for ISP implementation-only partially } \\
\text { funded } \\
\text { Issue a year-end report }\end{array}$ & Puglisi \\
$9 / 30 / 0303$ & Puglisi/Gurevitch \\
\hline
\end{tabular}




\subsubsection{Data Collection and Analysis Task}

Principal Investigator: Watts

\section{Scope}

This task plays an crucial role in the integrated surveillance program. Task products consists of three databases, which are coordinated through the Laboratory and distributed throughout the DOE Complex. These databases collect data from and support Rocky Flats, SRS, Hanford, Lawrence Livermore National Laboratory, and Los Alamos. Databases associated with ISP include the following:

- The Complex-Wide, integrated-surveillance-plan database coordinates core-required data fields detailed in the ISP, as well as any additional items specific to shipper-receiver agreements (Memorandum of Agreement, or MOA) between all shipping sites and SRS (these agreements include items generated at SRS).

- The MIS database records test and study results from SRS, Hanford, and Los Alamos efforts. It also compiles items and associated scientific reports originating from Hanford, Rocky Flats, and Los Alamos.

- The site-specific database serves as a repository for

- shelf-life studies funded through the 94-1 R\&D Program;

- surveillance results from 94-1 R\&D efforts, as well as information from sitespecific surveillance programs plus DP, 94-1 DP, Aries MD, and Fuel Studies $\mathrm{MD}$;

- coordinating the core-required data fields detailed in the ISP, as well as any additional items specific to shipper-receiver agreements (MOAs) between Los Alamos and SRS and any relevant and readily available information as referenced in the ISP.

\section{Issues}

- For an integrated (Complex-wide) surveillance program to work, sites must make available information that can be used to analyze, compare, and predict performance.

- Because shipping delays at generator sites have delayed data transmittal to Los Alamos for inclusion into the ISP, some containers are close to being one year old, which means they no longer are covered by the generators' site-specific surveillance plans. So that DOE, the MIS working group, and the ISP steering committee can provide adequate surveillance of these materials as part of the ISP, the Laboratory has requested preliminary data from generators so that monitoring and surveillance can begin before materials are shipped to SRS.

\section{Approach}

We will conduct the following activities during FY03:

- Publish schedule regarding the distribution of site-specific databases to the sites.

- Provide site-specific databases to sites.

- Work with SRS to determine site-specific anomalies and thus help facilitate MOAs.

- Work with SRS to help establish data-delivery schedules Complex-wide.

- Complete MOA between SRS and Laboratory ISP. 
- Initiate addendum to ISP that will allow dataflow to begin even if a generation site is unable to ship.

- Provide training on site-specific databases.

- Serve as technical lead when responding to site database issues.

- Use the Trusted File Transfer System to create open access to the Complex-wide ISP database.

- Analyze and publish data from generation sites; place specific emphasis on failure profiles.

- Integrate Process Qualification Requirements to ensure data fidelity.

- Receive Rocky Flats site-specific database.

- Continue PCD assistance to RFETS, including scan line and database support.

- Provide working databases/product certification databases and support, including Software User Manual to SRS, Lawrence Livermore National Laboratory, Hanford, and Los Alamos (already established at RFETS).

- Expand integrated surveillance database by adding to the RFETS data from sources such as SRS, Lawrence Livermore National Laboratory, Hanford, and Los Alamos.

- Share with MIS working group information related to all items and support documentation for all data found in the database.

- Produce and distribute software that visualizes prompt-gamma files, which already are available on the MIS website.

- Continue to maintain and update MIS Web site, including work in progress, authorizing documents, and new-item observations.

- Work with SRS and Los Alamos to determine site-specific anomalies unique to Los Alamos processing and facilitating.

- Work with SRS to help establish Los Alamos data-delivery schedule.

- Capture data obtained from small- and large-can studies.

- Create a secure Web interface to PF-4.

- Initiate internal review of data.

- Create methodology to conduct international promotion.

- Capture data obtained from destructive analysis.

- Monitor pressure-indicating devices.

- Capture radiographs.

- Facilitate analytical review and visualization of SRS items.

- Integrate process qualification requirements to ensure data fidelity.

- Update backlog of MIS data obtained from new or reprocessed items.

- Use MASS to obtain new characterization and shipper-receiver data.

- Use LIMS to obtain new data for chemical analyses.

- Post new data (using process data certified by the Process Qualification Plan) to Web site; the MIS working group will review the data.

- Create process flow charts for inclusion of data into the Complex-wide surveillance database.

- Update photo-catalog for new or backlogged items.

The following table lists activities that are identified as issues but are not funded. 
Issue or activity not funded

Funds are inadequate to support electronic archiving of RF-processing data books.
Additional funds needed

$\$ 100 \mathrm{~K}$

\section{Deliverables}

\begin{tabular}{l|l|l} 
Date Description & PI
\end{tabular}

\begin{tabular}{l|l|l}
\hline 9/30/03 & Issue year-end report & Watts
\end{tabular}




\subsubsection{Shelf-Life Studies}

Principal Investigator: Worl

\section{Scope}

This task's objective is to develop the technical basis for safely storing plutonium-bearing materials in sealed 3013 containers. We will test the long-term performance of containers, as well as stored materials in small- and full-scale containers. We will use shelf-life surveillance information to identify categories of materials that are at a higher risk for causing container failure; such work will help focus ISP surveillance activities. Additionally, these data will provide basic information that will contribute to efforts in gas generation and behavior modeling.

\section{Issues}

- So far, materials that were tested exhibit minimal gas generation. However, only a small portion of material from MIS items has undergone testing.

- To ensure that material is safely stored, we must conduct accelerated testing that expands the boundaries of temperature, moisture content, and impurities.

- A system failure (in this case, a breach in the other container) typically results from unforeseen conditions.

\section{Approach}

We will conduct the following activities during FY03:

- Use small-scale containers to hold MIS inventory materials, as well as controlled mixtures of actinide oxides and impurities.

- Use parametric studies to (1) evaluate material composition and water-content boundaries and (2) assess the safe-storage envelope.

- Conduct tests to identify any unforeseen and unidentified conditions that may yield problems.

- Load both container types with oxide materials and monitor said containers over time.

- Use large-scale containers to evaluate baseline plutonium oxides, oxides exposed to highhumidity atmospheres, and oxides containing chloride salt impurities.

- Include samples from materials packaged for storage.

- Use shelf-live surveillance to provide the DOE Complex with a mechanism for gathering, interpreting, and reporting experimental storage data on plutonium-bearing materials.

The following table lists activities that are identified as issues but are not funded.

\section{Issue or activity not funded}

Pressure-chamber and container deflagration/ detonation tests are needed to demonstrate the safety of the can-puncture system.

Consultant not funded.

\section{Additional funds needed}

$\$ 200 \mathrm{~K}$

$\$ 30 \mathrm{~K}$ 


\section{Deliverables}

Date Description $\quad$ PI

\begin{tabular}{|l|l|l|}
\hline $12 / 30 / 02$ & Load one small-scale capsule & Worl
\end{tabular}

\begin{tabular}{|l|l|l|}
$2 / 25 / 03$ & Complete the RA for the full-scale tests & Worl
\end{tabular}

7/14/03 Complete loading and begin testing of four full-scale $\quad$ Worl

\begin{tabular}{l|l|l} 
9/30/03 & Issue a year-end report & Worl
\end{tabular} 


\title{
3.2.5 Outer 3013 Container Lead Surveillance Program
}

Principal Investigator: Dunn

\begin{abstract}
Scope
Personnel assigned to this task develop 3013 packages loaded with surrogate materials to (1) lead the storage stockpile in terms of package degradation, (2) monitor the degradation of packages over time both non-destructively and destructively, and (3) develop techniques and a methodology that can help storage sites identify suspect packages. Storing and analyzing lead containers will provide the necessary data to validate performance (based on degradation models developed through the MIS program) and subsequently provide samples that lead the storage inventory. SRS will develop (1) a methodology to monitor the container degradation rate and (2) a mechanism for the surveillance population. The latter effort will provide a predictive capability for determining which $\mathrm{Pu}$-bearing 3013 containers are at the greatest risk for failure. With such knowledge, personnel can apply mitigation technologies before such failures.
\end{abstract}

\section{Issues}

A viable lead-surveillance program is the only viable way to ensure the safe, efficient, and longterm storage of 3013 containers at SRS and across the DOE Complex. An alternative to a leadsurveillance program is a statistically based, full-inventory surveillance program that far exceeds the "minimal surveillance" recommendation in DOE Standard 3013.

\section{Approach}

We will conduct the following activities during FY03:

- Evaluate the use of commercially available equipment and industry-accepted methods to assess wall thinning, stress-corrosion cracking, and pitting-corrosion nondestructively. These methods may include radiography, ultrasonic inspection, and interferometry.

- Procure and test NDE equipment. Testing instrumentation should include establishing the limits of detectability in prototypical cracks (e.g., generated via fatigue cracking) and simulated corrosion pits (e.g., generated via laser penetration). These detectability limits will determine how an instrument is used and what conclusions may be drawn from the data generated from it.

- Establish an engineering protocol for employing NDE equipment and analyzing the resultant data. For example, when using ultrasound to detect a specifically sized crack, what are the parameters (device specific and scan interval) engineers should use when conducting NDA inspections?

- Conduct full-scale experiments for 3013 using surrogate material for the plutonium oxide. Such a scale will us to perform a much more detailed and cost-effective study.

- Use data from storage and analysis of 3013 containers to validate performance (based on degradation models developed through the 94-1 R\&D Program) and subsequently provide samples that lead the storage inventory.

- Note that the parameters used in this population (such as humidity, temperature, pressure, and salt content) will reflect mechanisms currently identified by the 94-1 R\&D Program as having the highest failure probability in the stockpile. 
- Our work also will establish an SRS methodology, as well as the capability to monitor the container-degradation rate and mechanism for the surveillance population.

- Use data collected from these studies to refine further the corrosion studies performed at Los Alamos.

The following table lists activities that are identified as issues but are not funded.

Issue or activity not funded

Additional funds needed

N/A

Deliverables

\section{Date Description}

PI

Issue a report on the stress corrosion cracking and pitting mechanisms

Complete installation of ACRMS in full-scale, shelf-life containers

Issue a report on corrosion monitoring in full-scale, shelf-life containers

9/30/03 Issue a year-end report 


\subsubsection{Container Pressure Measurements Task Principal Investigators: Szempruch and Rennie}

\section{Scope}

The purpose of this task is to monitor the pressure of containers at Hanford. We also will analyze in situ pressure measurements taken from Hanford pressure-sensor data.

\section{Issues}

The technical basis is still very "lean" in that it lacks data demonstrating limited pressure generation in 3013 containers. Such containers are sealed and experience higher temperatures than containers typically observed in traditional storage settings.

\section{Approach}

No activities are funded for FY03. The following table lists activities that are identified as issues but are not funded.

\section{Issue or activity not funded}

Support data analysis and reporting of pressure measurements at Hanford.

Purchase a few instruments from Hanford and install the devices on Laboratory containers.

Evaluate the feasibility of pressure measurements in 3013 containers at Los Alamos.
Additional funds needed

$\$ 100 \mathrm{~K}$

$\$ 100 \mathrm{~K}$

$\$ 20 \mathrm{~K}$

\section{Deliverables}

\begin{tabular}{l|l|l} 
Date & Description & PI \\
\hline $\begin{array}{l}\text { Not } \\
\text { funded }\end{array}$ & $\begin{array}{l}\text { Report on the performance and data of the Hanford pressure } \\
\text { measurements }\end{array}$ & Not assigned \\
9/30/03 & $\begin{array}{l}\text { Issue a year-end report } \\
\end{array}$
\end{tabular}




\subsubsection{Container and Material Interactions Task}

Principal Investigator: Paffett

\section{Scope}

The purpose of this task is to identify the probability and associated risk (if a finite probability exists) of corrosion-related failure mechanisms in 3013 containers.

\section{Issues}

- We know little about the properties and behavior of various processing salts that are inside stainless-steel containers at expected storage conditions found at KAMS.

- We must understand the form, distribution, and deliquescent properties of salts if we are to stabilize and store such materials in 3013 containers at KAMS. Salt characteristics we must better understand include high water sorption capacity of some salts at low relative humidities, as well as their potential to be sources for radiolytically produced corrosives such as $\mathrm{HCl}$.

- Although the 3013 container has been designed to minimize corrosion-related failure, we do not know the risks associated with the possibility of corrosion failures during the 50year storage of stabilized plutonium-bearing materials. To date, observations of material performance have been anecdotal.

\section{Approach}

Researchers will expose 3013 container materials and their welds to stress, ionizing radiation, elevated temperatures, embrittling agents (e.g., gallium and plutonium), halide-containing compounds (e.g., $\mathrm{Cl}^{-} / \mathrm{F}^{-}$), and moisture. Although all these environmental conditions are deleterious to material integrity under certain conditions, the four most probable failure modes for 3013 containers are as follows:

- localized corrosion,

- stress corrosion cracking (SCC),

- embrittlement (liquid metal embrittlement, LME, and Ga-induced embrittlement), and

- radiation-assisted corrosion.

We will evaluate each of these mechanisms as it relates to 3013 containers that hold plutonium oxide with associated impurities and are stored under conditions anticipated at the KAMS facility.

We will conduct the following activities during FY03:

- Assess in situ corrosion characteristics of 3013 materials in environments relevant to the interiors of 3013 cans.

- Address deliquescence and surface morphological questions that arise from salt mixtures with plutonium-bearing materials possessing significant surface areas $\left(>2 \mathrm{~m}^{2} / \mathrm{gm}\right)$, as well as those related to examining corroding interfaces at relevant partial pressures of water.

- Support ISP through the destructive evaluation/inspection of 3013 containers. 
- Use the environmental scanning electron microscope (ESEM) to identify incipient corrosion events and characterize the elemental composition of the corroding area.

- Use ESEM to identify morphological and elemental characteristics of corrosion pits in stainless steel.

- Study the morphological and deliquescent properties of various processing salts and salt/oxide mixtures in support of 3013 stabilization.

- Determine current by conducting a literature study on corrosion-related failure mechanisms, including embrittlement, localized corrosion/chloride-induced failure, SCC, and the influence of irradiation.

- Define SCC problem as it applies to 3013 environments.

- Determine the threshold stress intensity for SS316L/welds in a variety of 3013 prototypical environments.

Future activities include the following:

- Develop a model for failure that integrates residual-stress data, pressurization predictions, and projected pit depths along with crack propagation rates.

- Develop lifetime projection for 3013 as it relates to failure caused by SCC.

- Investigate the influence of primary radiolysis products (e.g., $\mathrm{OH}$ radical) on corrosion rates, as well as $\mathrm{H}_{2} \mathrm{O}_{2}$ (cathodic reactant) production rates for $\mathrm{Pu}$ oxide articles.

- Develop model that simulates radiation-assisted corrosion.

- Use destructive metallographic methods to identify industry-accepted methods to evaluate wall thinning, SCC, and pitting corrosion.

- Determine each technique's detectability limits for prototypical cracks and pits.

- Determine the production rates of $\mathrm{H}_{2} \mathrm{O}_{2}$ at $\mathrm{Pu}$ oxide surfaces.

- Determine the radiolysis products at the container/Pu-ox interface.

- Collect electrochemical data on corrosion kinetics as a function of radiation type, flux, and fluence.

- Develop radiation-assisted corrosion model that integrates $\mathrm{H}_{2} \mathrm{O}_{2}$ production rates and primary products.

- Evaluate how radiation influences corrosion mechanisms.

- Develop an engineering method to apply 94-1 Core Tech Lifetime projections to an ISP.

- Evaluate lead surveillance data within the context of 94-1 Core Tech Lifetime projections and establish a protocol for conducting 3013 surveillance.

- Complete metallographic analysis of samples exposed to chlorides.

- Complete statistical (GEV) analysis of samples exposed to chlorides.

- Evaluate potential corrosion (SCC and pitting) mechanisms for 3013 failure modes at SRS and Los Alamos.

- Fabricate and install ACRMs in 3013 shelf-life cans.

- Collect initial data for proof of concept.

- Evaluate stress data for stainless-steel 316 and weld zone as a function of environment.

- Conduct furnace corrosion studies. 
The following table lists activities that are identified as issues but are not funded.

Issue or activity not funded

Stainless-steel/plutonium-metal interaction study.
Additional funds needed

$\$ 200 K$

\section{Deliverables}

\begin{tabular}{|c|c|c|}
\hline Date & Description & PI \\
\hline $10 / 1 / 02$ & Develop SCC Project Plan (with SRTC researchers) & \\
\hline $10 / 1 / 02$ & $\begin{array}{l}\text { Issue a national test plan to evaluate SCC_-coordinated effort } \\
\text { between SRS and Los Alamos }\end{array}$ & Lillard \\
\hline $10 / 1 / 02$ & Issue a report on boat- and furnace-corrosion observations & Lillard/Hollis \\
\hline $8 / 30 / 03$ & $\begin{array}{l}\text { Issue a report detailing the results of the corrosion monitors in } \\
\text { full-scale shelf-life items }\end{array}$ & Lillard \\
\hline $8 / 30 / 03$ & $\begin{array}{l}\text { Issue a report discussing the methodologies of SCC } \\
\text { evaluations }\end{array}$ & Lillard \\
\hline
\end{tabular}




\title{
3.2.8 Gas Generation and Modeling \\ Principal Investigator: Paffett
}

\begin{abstract}
Scope
For this task, we will develop and design a model and associated computer code to predict gas generation and behavior in 3013 containers during shipment and storage. Researches will use the product code to evaluate transportation, storage, and facility safety.

Modeling efforts beyond the simple cases consist of those that incorporate only (1) gas-phase reaction chemistry (e.g., CHEMKIN) or (2) radiation-derived modeling (e.g., RadCALC). The Los Alamos model presently includes a recombination reaction wherein radiolytically produced hydrogen consumes molecular oxygen, thereby increasing the hydrogen's gas-phase mole fraction. We must include rates and source terms that drive gas generation to ensure the integrity of transported packages and in particular address short-term concerns applicable to transportation scenarios.
\end{abstract}

The principal objective of this task is to address a fundamental information gap in radiation chemistry that has enormous implications in our understanding - and thus or ability to correctly model-gas generation that arises from radiolysis events occurring within monolayer quantities of adsorbates on material and material mixtures.

\section{Issues}

- To model gas generation accurately, we must understand the fundamentals of adsorbed water and salt radiolysis as it relates to plutonium storage environments.

- Occurring at much faster rates than radiolysis events, $\mathrm{H}_{2}+\mathrm{O}_{2}$ recombination reactions have been shown (through experimental measurements) to decrease canister pressures. In addition, this important back reaction may significantly alleviate the production of hazardous gas mixtures.

- The DOE Complex does not have a definitive technical basis to demonstrate that oxygen and hydrogen cannot co-exist in a 3013 container or a food-pack can container.

- The DOE Complex does not have predictive capabilities for pressure and evolved gasses. Such predictive capabilities will play a crucial role in conducting safety analyses for processing and testing.

- There are gaps in our understanding of gas-generation rates.

- We need a stronger experimental database from which to build predictive models.

- Before Environmental Management (USDOE-EM) can transport nuclear material forms to other sites for further disposition, it must minimize the potential for radiolytic gas generation to pressurize transportation and storage containers.

- Our limited understanding of the fundamental processes that contribute to gas generation has impeded our ability to predict canister pressures and gas-phase compositions.

- Presently, simple approximations and mathematical models yield conservative results that are unwarranted for low-moisture-content actinide oxide materials. This overly conservative approach for predicting gas generation leads to increased costs for materials management of low-moisture-content materials.

- The absence of a reliable and validated modeling procedure leads to expensive testing and frequent delays. 
- We should also determine if it is possible to extend validated computer models for gas generation beyond their traditional case limits.

- To date, research and studies show that only minimal gasses result from initial fill gas and helium in-growth. The cause is hydrogen gas, which results from the chemical and radiolytic decomposition of moisture.

- The maximum allowable pressure of a 3013 container is 714 psia. A container could exceed this theoretical pressure if factors such as container-free volume and storage temperature were not controlled. However, minimal pressures on the order of 10 psia have been recorded for convenience cans and welded materials both within and outside the 94-1 R\&D Program. Thus, researchers feel that modifying the pressure equation so that it more accurately reflects the expected gas-generation rate would result in significant cost and schedule benefits.

- Some scientists feel that modifying the pressure equation to reflect more accurately the expected gas-generation rate could result in significant cost and schedule benefits. However, the basis for these low pressures is not very well understood. There are data gaps that provide a technical basis to support a revision.

We will conduct the following activities during FY03:

- Use gamma and alpha irradiation to measure $\mathrm{H}_{2}$ generation rates (as well as $\mathrm{O}_{2}$ ) for a wide range of particle size/surface areas.

- Develop a model for well-defined $\mathrm{PuO}_{2}$ materials with different water loadings.

- Extend model and validate against empirical data with high-water loadings.

- Collect data and consider mechanisms with different salt contents.

- Develop solutions and test these against preliminary data from mixed salt $\mathrm{PuO}_{2}$ material.

- Extend modeling efforts so that we can understand and predict gas-generation behavior on actinide materials in sealed containers.

- Refine empirical and molecularly based gas-generation models by applying data provided by experimentalists at Hanford, SRS, and Los Alamos.

- Extend present modeling efforts so that they take into consideration higher ( 2-3 wt. \%) water concentrations and mixtures made up of impure actinide oxide. Specifically extend modeling capability to address actinide oxide/salt mixtures (Appendix A contains results from the $1^{\text {st }}$ year effort).

- Provide collaborators with modeling assistance and input files for CHEMKIN-based mechanisms.

- Collaborate with scientists at the University of Notre Dame, Georgia Tech University, and Los Alamos to determine the fundamental role of radiolysis that results from complex interfacial mixtures of salt and actinide oxides (and/or surrogates).

The Notre Dame Radiation Laboratory will conduct the following activities during FY03:

- Use gamma and alpha irradiation sources to measure $\mathrm{H}_{2}$ for above oxides with a range of water layers.

- Evaluate new oxides to understand the band-gap issue.

- Continue to measure and study $\mathrm{H}_{2}\left(\mathrm{O}_{2}\right)$ (and if possible $\mathrm{HCl}$, and $\mathrm{Cl}_{2}$ ) from the following types of salts: anhydrous, hydrated, and wet. Irradiate $\mathrm{NaCl}$ and $\mathrm{KCl}$ salts as well. 
- Evaluate the issue of processing 3013 in various storage environments (i.e., rate of moisture pickup and radiation induced gas generation).

- Measure color center if possible.

- Conduct a micro-dosimetry of $\mathrm{PuO}_{2}$ : separate small-particle-size fractions of pure and impure $\mathrm{PuO}_{2}$ and characterize each size fraction.

- Test various micro-dosimetry methods for calculating dose.

- Conduct literature search on radiation-induced, corrosive gas generation in other impure materials at SRS and Hanford.

- Use data from long-term, small-scale test and ISP to predict G values and rate of gas generation.

- Analyze and report results. Prepare reports and publish in peer-reviewed journals.

The following table lists activities that are identified as issues but are not funded.

Issue or activity not funded

N/A
Additional funds needed

\section{Deliverables}

\begin{tabular}{l|l|l} 
Date & Description & PI \\
\hline Ongoing & $\begin{array}{l}\text { Model and fit Los Alamos data as the information becomes } \\
\text { available }\end{array}$ & Kelly \\
Ongoing & $\begin{array}{l}\text { Perform test-case modeling studies for containers filled at } \\
\text { RFETS and Hanford (as requested) }\end{array}$ & Paffett \\
12/15/02 & $\begin{array}{l}\text { Continue modeling SRTC data } \\
\text { Present results at ANS and AVS scientific symposia }\end{array}$ & Kelly \\
$3 / 1 / 03$ & Paffett \\
$4 / 14 / 03$ & $\begin{array}{l}\text { Develop model to incorporate mixed salt }+ \text { PuO }_{2} \text { data } \\
\text { Prepare full manuscript on gas generation from well-defined }\end{array}$ & Kelly \\
$5 / 1 / 03$ & Kelly/Paffett \\
materials (in concert w/SRS-TC data) for publication in & $\begin{array}{l}\text { J. Nuc. Materials } \\
\text { Issue "Radiolysis of Salts and Adsorbed Water" report } \\
\text { Prepare full manuscript on gas generation from well-defined } \\
\text { materials (in concert w/SRS-TC data) for publication in } \\
\text { J. Nuc. Materials }\end{array}$ & Tandon \\
Kelly/Paffett & \\
&
\end{tabular}




\subsubsection{SRTC Experimental Gas-Generation Studies \\ Principal Investigator: Livingston}

\section{Scope}

SRTC will provide experimental gas-generation support for the 94-1 R\&D Program. This effort will use small-scale gas-generation test apparatus to evaluate the impacts of 3013 storage conditions. Results of these tests will support Laboratory efforts to develop molecularly based gas-generation models. These small-scale tests will address factors that impact hydrogengeneration rates, gas composition, and steady-state pressures.

See section 3.2.7.

\section{Issues}

\section{Approach}

We will conduct the following activities during FY03:

- Support installation of TGA \& BET instruments to improve the characterization of test materials.

- Improve gas-generation test apparatus for small gas samples and elevated temperature tests.

- Continue to measure gas-generation rates for pure and impure oxides to support program needs.

- Investigate factors contributing to steady-state $\mathrm{H}_{2}$ pressures in 3013 contents.

- Support emerging program needs related to gas generation and 3013 storage.

- Incorporate the capability into the test apparatus to handle small corrosion specimens.

- Continue to participate in MIS \& JOWOG efforts.

- Disseminate research findings in technical reports and at conferences.

The following table lists activities that are identified as issues but are not funded.

Issue or activity not funded

N/A

\section{Additional funds needed}

\section{Deliverables}

\begin{tabular}{l|l|l} 
Date & Description & PI \\
\hline Quarterly & Update gas-rate/pressure results & Livingston \\
March 03 & Implement improved small-scale test apparatus & Livingston \\
June 03 & TGA/BET analysis of $\mathrm{PuO}_{2}$ test materials & Livingston \\
Sept 03 & Report on steady-state $\mathrm{H}_{2}$ pressure for 3013 storage & Livingston
\end{tabular}




\section{Capital}

The following equipment has been identified but has not been funded:

$\underline{\text { Issue or activity not funded }}$

Support for a ESEM

3013 container-puncture and gas-sampling equipment

PF-4 glovebox removal and installation

PF-4 hood installation

Containment vessel

Environment enclosure
Additional funds needed

$\$ 300 \mathrm{~K}$

$\$ 280 \mathrm{~K}$

$\$ 1 \mathrm{M}$

$\$ 200 \mathrm{~K}$

$\$ 40 \mathrm{~K}$

$\$ 60 \mathrm{~K}$ 


\subsection{Program Management}

Project Leader: Mason

\subsubsection{Program Coordination}

Project Leader: Mason

\section{Scope}

This task covers program coordination, integration, oversight, reporting, and reviews for (1) the overall 94-1 R\&D Program and (2) specific work performed for the following projects: Material Identification, Stabilization Technology Development, Surveillance and Monitoring Technology, and Core Technology. This work-breakdown structure also includes managing DOE-STD-3013, which includes periodic review and update of the standard as a result of new information obtained through continuing research and analysis of the standard's technical basis.

\section{Approach}

- Provide technical review and evaluations that support the biannual review of DOE-STD3013.

- Provide technical support to Hanford and SRS so that they can implement qualified processes.

- Provide as-requested technical support for immobilization activities that involve nonweapons-grade plutonium.

The following table lists activities that are identified as issues but are not funded.

\section{$\underline{\text { Issue or activity not funded }}$}

Ray Martin has minimal funding- $\$ 80 \mathrm{k}-$ to assist the NMI effort.

Contractor John Psaras has minimal funding $-\$ 25 \mathrm{k}$ - to provide general support.

Gary Eller has minimal funding of $\$ 25 \mathrm{k}$.

Technical report and program reviewers

Only the minimum $2 \%$ is set aside. Laboratory shuts down the codes when the costs plus commitments reach $98 \%$.
Additional funds needed

$\$ 80 \mathrm{~K}$

\$80K

$\$ 100 K$

$\$ 150 \mathrm{~K}$

$\$ 220 \mathrm{~K}$ 


\section{Deliverables}

\begin{tabular}{l|l|l} 
Date & Description & PI \\
\hline $10 / 26 / 02$ & Complete annual experimenters review and annual 94-1 & Dominguez/Mason \\
& R\&D Program review_Los Alamos & \\
$1 / 24 / 03$ & Complete first-quarter review_SRS & Dominguez/Mason \\
$4 / 25 / 03$ & $\begin{array}{l}\text { Complete semi-annual experimenters review and semi- } \\
\text { annual 94-1 R\&D Program review_Los Alamos }\end{array}$ & Dominguez/Mason \\
$7 / 25 / 03$ & $\begin{array}{l}\text { Complete third-quarter review_RFETS } \\
\text { 10/30/03 }\end{array}$ & $\begin{array}{l}\text { Dominguez/Mason } \\
\text { Issue year-end report }\end{array}$
\end{tabular}




\subsubsection{Standard Maintenance}

Principal Investigator: Vacant

\section{Scope}

The purpose of this task is to maintain the 3013 standard as a practical and technically sound paradigm used to stabilize, ship, and store plutonium metal and oxides with accompanying impurities.

\section{Issues}

A DOE standard must be reviewed and updated every two years.

\section{Approach}

We have no activities planned for FT03. The following table lists activities that are identified as issues but are not funded.

Issue or activity not funded

Additional funds needed

Collect information, write, review, and publish a revised 3013 standard.

Collect data, evaluate, write, review, and publish 3013 technical basis.

Write, review, and publish 3013 Guidance Document.

\section{Deliverables}

\begin{tabular}{l|l|l} 
Date & Description & PI \\
\hline None & &
\end{tabular}




\section{References}

An Implementation Plan for Stabilization and Storage of Nuclear Material: The Department of Energy Plan in response to DNFSB recommendation 2000-1 Revision 2 (July 2002).

DOE-STD-3013-2000 Stabilization, Packaging, and Storage of Plutonium Bearing Materials (September 2002).

"Paths to Closure-Status Report on Paths to Closure March 2000," DOE/EM-0526 (March 2000).

Strategy \& Technical Program Plan for the 94-1 R\&D Program-Fiscal Year 2003, LA-UR-024635.

Brief 94-1 R\&D Program Plan-2003 to termination. 
Work Packages 


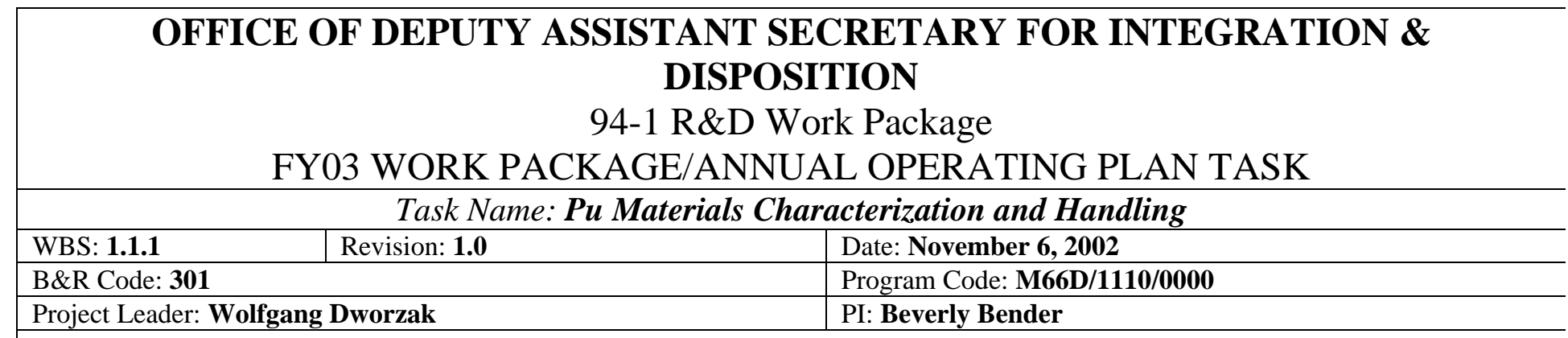

\section{FUNDING}

\begin{tabular}{|c|c|c|c|c|c|c|}
\hline Participant & Type & Staff & $\begin{array}{c}\text { Prior Year } \\
\text { Budget }\end{array}$ & $\begin{array}{c}\text { Prior Year } \\
\text { Uncosted }\end{array}$ & $\begin{array}{l}\text { Current } \\
\text { Budget }\end{array}$ & FY03 Plan* \\
\hline NMT-2 & Operating & & & & \$0K & $\$ 0$ \\
\hline NMT-11 & Operating & .85 TSM, 1 TECH5, 1.5 SSM & & & $\$ 756 K$ & $\$ 756 \mathrm{~K}$ \\
\hline NMT-15 & Operating & .1 TSM, .4 TECH5 & & & $\$ 120 \mathrm{~K}$ & $\$ 120 \mathrm{~K}$ \\
\hline NMT-16 & Operating & & & & $\$ 0 K$ & $\$ 0$ \\
\hline C-AAC & Operating & General Chemistry & & & $\$ 277 K$ & $\$ 277 \mathrm{~K}$ \\
\hline & & Total & & & $\$ 1.153 \mathrm{M}$ & $\$ 1.153 \mathrm{M}$ \\
\hline
\end{tabular}

*Amount in this column is the planned task budget for FY03. The current Budget may be less if the task is funded incrementally.

\section{MILESTONES AND DELIVERABLES}

\begin{tabular}{|l|l|l|l}
\hline No. & \multicolumn{1}{|c|}{ Description } & \multicolumn{1}{|c}{ Responsible Participant } & Completion Date \\
\hline $\mathbf{1}$ & $\begin{array}{l}\text { Complete characterization and issue report on the two } \\
\text { Hanford items received in FY02 }\end{array}$ & B. Bender & \\
\hline $\mathbf{2}$ & Characterization & E. Wilson, B. Bender & $\mathbf{5 / 1 5 / 0 3}$ \\
\hline $\mathbf{3}$ & Re-Evaluation & E. Wilson, B. Bender & \\
\hline $\mathbf{4}$ & Support NM, TGA, Disposition, Prompt Gamma & B. Bender & \\
\hline $\mathbf{5}$ & Glovebox Replacement & E. Wilson, B. Bender & \\
\hline $\mathbf{6}$ & Shelf-Life Support & E. Wilson, B. Bender & \\
\hline $\mathbf{7}$ & Issue MIS item characterization report & B. Bender & $\mathbf{8 / 3 0 / 0 3}$ \\
\hline $\mathbf{8}$ & Issue a white paper of materials that should be evaluated & W. Dworzak & $\mathbf{1 / 3 0 / 0 3}$ \\
\hline $\mathbf{9}$ & Issue year end report & B. Bender & $\mathbf{9 / 3 0 / 0 3}$ \\
\hline
\end{tabular}

\section{REVISIONS}

\begin{tabular}{|l|c|l}
\hline Rev No. & Date & Revision \\
\hline $\mathbf{1 . 0}$ & $\mathbf{1 1 / 6 / 0 2}$ & \\
\hline & & \\
\hline
\end{tabular}

\section{WORK SCOPE}

The Pu materials Characterization and Handling Task are the keystone operation for any activity that uses special nuclear material (SNM). The objectives of this task are to 1) receive items from different sites; 2) demonstrate adequate stabilization of plutonium bearing materials; 3 ) characterize materials (physical and chemical characterization) that from the sites and add them to the MIS inventory after passing the evaluation; 4) maintain the MIS inventory; 5) provide SNM to experiments working on other tasks and activities of the $94-1$ project. 
Issue(s):

- Processing and safe storage ultimately depends on the material that is packaged. Many stabilization and packaging sites no longer have the analytical capabilities to characterize unusual or problem materials. Consequently, these materials must be sent to Los Alamos where the capabilities still exist.

- The MIS inventory needs to be maintained until all of the stored material it represents is process an no longer in the EM inventory. These materials need to be on hand for future evaluations incase problems in stabilizing or storage appear.

- The physical and chemical character of many items in the complex that may influence processing, equipment performance, and safe storage are not known.

- $\quad$ Synergistic combinations of different materials.

Scope:

Plutonium is found in combination with wide variety of impurities and so to assure long-term safe storage the DOE-STD-3013 storage standard requires that the chemical and physical characteristics of all stabilized and packaged plutonium-bearing materials be identified. Once the chemical and physical characteristics of the stabilized material are understood the material is "represented" in the MIS inventory. Under this task LANL facilitates discussions with the stabilization, packaging, and storage sites to evaluate the site inventories for representation in the MIS inventory, performs chemical and physical characterization of the pre- and post- stabilized material, and processes the material to demonstrate that the stabilization process is adequate for the different material types. In this task, materials will be processed, sampled, and data collected. Because of anomalous behavior of a few items in the MIS/CMR moisture measurement study a few of the previously tested MIS items will be re-evaluated. After the examinations are completed they will be calcined at 950C for a final time and packaged in a 3013 container. This task is essential to the 94-1 R\&D Program since it supports all testing and experimentation that is performed with radioactive materials. Additionally, characterization techniques are developed in this task. Development of the prompt gamma technique to measure specific impurities in the bulk material will continue. This technique will provide an invaluable tool to the storage sites and for disposition planning since it allows identification of impurities in the welded 3013 containers.

Approach:

The following activities are planned for FY03:

- Identify actinide materials requiring stabilization, packaging, and storage.

- Develop technical basis and analytical data to stabilize and store impure materials in 3013 containers, specifically materials with only 30 to $50 \%$ plutonium.

- Evaluate new and anomalous (anomalous re-adsorption and chemistry results) materials to support representation in MIS inventory.

- Receive food pack containers from the complex and sample headspace gases.

- Maintain Material Identification and Surveillance Inventory.

- Support TGA instrument development by providing characterization data and SNM samples.

- Support neutron moderation instrument development by providing characterization data and SNM samples.

- Support shelf-life task by providing characterization data and SNM samples.

- Support prompt gamma development by providing characterization data and SNM samples.

- Clean out glove box in room 212 and prepare box for processing MIS materials. 
Signatures:

NMT-11 Group Leader

NMT-15 Group Leader

C-AAC Group Leader

Principal Investigator

Project Leader

Program Leader
Date

Date

Date

Date

Date

Date 


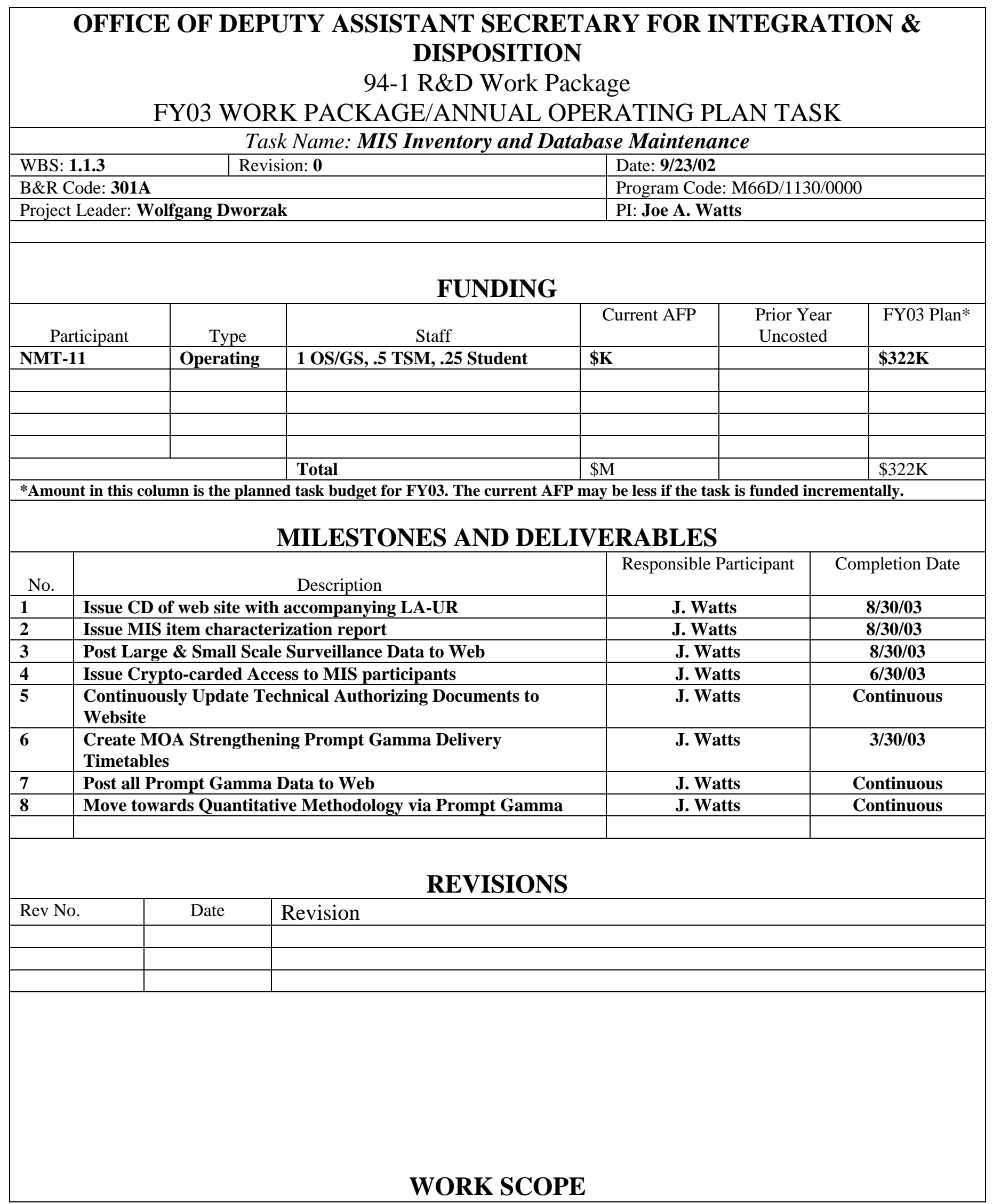


The Inventory and Database Maintenance Task conduits the flow of data from Processing Personnel to Data Inventory and Analysis Personnel. The data is collected sorted into logical groupings and put into the 94-1 World Wide Web (WWW)

Database and Integrated Surveillance Plan (ISP) databases. The combination of both databases and the data contained within serves all of the sites across the complex and helps to facilitate mission critical objectives such as the closure of RFETS and the disposition of items. The databases contain both analyzed and unanalyzed data.

Typical data groupings are Characterization data and Process Datamaps, Prompt Gamma, Thermographic Analysis (TGA), XRay Diffraction (XRD), Photographs of Inner, Outer, and Inner with Contents, Radiographs, Particle Size Analysis, Elemental Analysis, and Weight Change Analysis. In addition, various reports and publications essential to the program needs of the sites can be accessed from the website, for example: Item Assemblies, Can Opening Devices, Sampling Systems; Work in Progress Items such Moisture Measurement, and TGA FTIR/MS, Neutron Moderation, Furnace Failure Presentations, Authorization Documents, Technical and Project Status Reports.

Issue(s):

- If a process or storage issue is identified the solution is usually needed in a short time.

- If represented materials are not available then time is lost getting the material into the R\&D pipeline

- Tremendous volumes of data require time and personnel to organize and analyze

- New data has been generated in support of TGA IR/MS and Processing at Rocky Flats the Working Databases and Product Certification Databases across the complex will have to be updated to reflect the need for this analysis at all of the shipper receiver sites.

- As new Sites make contributions to the data streams, what percentage of analysis has been Quality Controlled and Assured

Approach:

Update data as new analyses or processing steps are completed

Review all published data and verify data

Improve the readability of the database and web site

Maintain the publications list

- Work with Processing Personnel to aggregate all data accumulated related to site support and disposition of materials to receiver sites

- Analyze all data derived from processing in support of site closure and disposition of material 
Signatures:

NMT-11 Group Leader : D. Bennett

Principal Investigator: Joe A. Watts

94-1 R\&D Project Leader: R. E. Mason $\underline{11 / 20 / 02}$

Date

$\underline{11 / 20 / 02}$

Date

$\underline{11 / 20 / 02}$

Date 


\begin{tabular}{|c|c|c|c|c|c|c|c|c|c|}
\hline \multicolumn{10}{|c|}{$\begin{array}{c}\text { OFFICE OF DEPUTY ASSISTANT SECRETARY FOR INTEGRATION \& } \\
\text { DISPOSITION } \\
\text { 94-1 R\&D Work Package } \\
\text { FY03 ANNUAL OPERATING PLAN TASK }\end{array}$} \\
\hline \multicolumn{10}{|c|}{ Task Name: Implementation of NDA Analysis Methods } \\
\hline \multicolumn{5}{|c|}{ Revision:0 } & \multicolumn{5}{|c|}{ Date:11/5/02 } \\
\hline \multicolumn{5}{|c|}{ B\&R Code: 301A } & \multicolumn{5}{|c|}{ Program Code: M26D/1140/0000 } \\
\hline \multicolumn{5}{|c|}{ Project Leader: Wolfgang Dworzak } & \multicolumn{5}{|c|}{ PI: L. Morales, K. Hollis, L. Foster } \\
\hline \multicolumn{10}{|c|}{ FUNDING } \\
\hline \multirow{2}{*}{\multicolumn{2}{|c|}{$\begin{array}{l}\text { Participant } \\
\text { NMT-4 }\end{array}$}} & \multicolumn{2}{|c|}{ Type } & \multicolumn{2}{|l|}{ Staff } & Current AFP & \multicolumn{2}{|c|}{$\begin{array}{l}\text { Prior Year } \\
\text { Uncosted }\end{array}$} & $\begin{array}{l}\text { FY03 } \\
\text { Plan* }\end{array}$ \\
\hline & & \multicolumn{2}{|c|}{ Operating } & & $\$ \mathbf{K}$ & & & $\$ 103 K$ \\
\hline \multicolumn{2}{|c|}{$\mathrm{X}-5$} & \multicolumn{2}{|c|}{ Operating } & \multicolumn{2}{|l|}{.25 TSM } & \$K & & & $\$ 25 K$ \\
\hline \multicolumn{2}{|c|}{ C-ACT } & \multicolumn{2}{|c|}{ Operating } & \multicolumn{2}{|l|}{.1 TSM, .25 TEC6 } & \$K & & & $\$ 86 K$ \\
\hline \multicolumn{2}{|c|}{ NMT-11 } & \multicolumn{2}{|c|}{ Operating } & \multicolumn{2}{|l|}{ 1 Student } & $\$ K$ & & & $\$ 109 K$ \\
\hline \multicolumn{2}{|c|}{ NMT-16 } & \multicolumn{2}{|c|}{ Operating } & \multicolumn{2}{|l|}{1 TSM, 1 TEC6 } & $\$ K$ & & & $\$ 578 \mathrm{~K}$ \\
\hline \multirow{2}{*}{\multicolumn{2}{|c|}{ C-ACT }} & $\mathbf{C a}$ & & TGA Ordered in FY0 & & $\$ 290 K$ & $\$ 257 \mathrm{~K}$ & & $\$ 300 \mathrm{~K}$ \\
\hline & & & & Total & & $\$ 290 \mathrm{~K}$ & $\$ 257 \mathrm{~K}$ & & $\$ 1.201 \mathrm{M}$ \\
\hline *Amo & nt in & the & d ta & budget for FY03. The cu & $\mathbf{A F P}$ & ay be less if the $t$ & task is $f$ & inded $\mathrm{i}$ & mentally. \\
\hline & & & IL] & STONES AND I & [V] & ERABLES & & & \\
\hline No. & & & escri & tion & & esponsible Partici] & pant & Com & letion Date \\
\hline 1 & $\operatorname{Rep}$ & $\operatorname{ard~} \mathrm{I}$ & expe & ments & L. 1 & oster & & $3 / 03$ & \\
\hline 2 & Issu & iical & $\mathbf{S R}$ & $\operatorname{ort}($ Rev.0) & L. 1 & oster/R. Martin & & $4 / 03$ & \\
\hline 3 & Issu & iical & $\mathbf{S \mathbf { R e }}$ & $\operatorname{ort}($ Rev.1) & L. 1 & oster/R. Martin & & $9 / 03$ & \\
\hline 4 & Issu & $\mathbf{m m}$ & hnic & l Basis & L. 1 & oster/J. Narlesk & & $3 / 03$ & \\
\hline 5 & Issu & $\mathbf{m m}$ & aluat & ons Report (Rev. 1) & & oster/J. Narlesk & & $8 / 03$ & \\
\hline 6 & Con & atio & hori & ation TGA/MS & & Hollis & & $12 / 02$ & \\
\hline 7 & Issu & $\operatorname{sis} \mathbf{R}$ & & & & Hollis & & $12 / 03$ & \\
\hline 8 & $\begin{array}{l}\text { Issu } \\
\text { Rep }\end{array}$ & ff the & $\overline{\mathbf{A} / \mathbf{M}}$ & /FTIR Technical Basis & & Morales & & $3 / 03$ & \\
\hline 9 & $\begin{array}{l}\text { Issu } \\
\text { Rep }\end{array}$ & ff th & $\overline{\mathbf{A} / \mathbf{M}}$ & /FTIR Technical Basis & & Morales & & $8 / 03$ & \\
\hline & & & & REVISIC & & & & & \\
\hline $\operatorname{Rev~I}$ & & ate & & ision & & & & & \\
\hline & & & & & & & & & \\
\hline & & & & & & & & & \\
\hline
\end{tabular}




\section{WORK SCOPE}

The implementation of NDA Analysis Methods task is crucial operation for the sites to complete stabilization and packaging of plutonium bearing materials. The objectives of this task are:

TGA Development and Support:

- $\quad$ TGA/MS/FTIR support and representative sample verification are required

Issue(s):

Prompt Gamma:

- The chemistry of many items is unknown - prompt gamma is a inexpensive and quick analysis method

- Prompt gamma's accuracy and precision is undetermined for many elements

- Prompt gamma analysis is a new chemical analysis method thus the accuracy and precision of the instrument is not fully demonstrated

Neutron Moderation:

- The precision and accuracy of NMI needs to be developed

- Small samples introduce sampling errors NMI samples most of the material

- Interference of actinides other than $\mathrm{Pu}$ is undetermined

\section{TGA Development and Support:}

- $\quad$ Certification of TGA/MS/FTIR for representative samples for complex.

- $\quad$ TGA-MS and TGA-FTIR are new instruments to the field of moisture measurement and the robustness of the techniques is not yet demonstrated.

- Only a portion of the MIS inventory materials have been evaluated. Although no analysis problems are anticipated difficulties with equipment maintenance when pressing impure materials are anticipated.

Scope:

The implementation of NDA Analysis Methods task is a crucial operation for the sites to complete stabilization and packaging of plutonium bearing materials. The objectives of this task are to provide the DOE complex with analytical tools to measure the moisture, composition, and container condition.

Approach:

Prompt Gamma:

- $\quad$ Perform experiments for Prompt Gamma to determine capabilities. (NMT-11, NMT-4)

- $\quad$ Perform prompt gamma studies to expand capability for measurement of impurities in packaged materials at LANL and Hanford. (NMT-11, NMT-4)

- $\quad$ Deploy prompt gamma capability to HF and SRS. (TBD)

- Neutron Moderation Instrument (NMI)

- $\quad$ Validate NMI operation by testing at LANL and Hanford. (NMT-4)

- Deploy NMI instruments at RFETS, LANL, and SRS. (C-ACT)

- Develop NDA instruments to meet the needs of processing and storage sites. (TBD)

- $\quad$ Perform parametric studies to evaluate the effectiveness of NMI when impurities are present. (X-5)

- TGA Development and Support. 
TGA Development and Support:

- A TGA/MS instrument was purchased in FY02. The instrument will be installed at TA-35, Building 85W. NMT-14 will be requested to attend the process hazard analysis and will be given all documentation from this process for reference in their authorization development for TA-55. Once the work is authorized, C-ACT personnel will be available for operational training of the instrument for NMT and other 94-1 program personnel. (C-ACT)

- Measure moisture on MIS samples by SFE as samples are submitted. (C-ACT)

- $\quad$ Evaluate impure MIS materials with TGA-MS and TGA-FTIR analyses. (NMT-16, NMT-11)

- $\quad$ Support process qualification applications with TGA-MS and TGA-FTIR analyses. (NMT-16)

- $\quad$ Support RFETS closure activities with TGA-MS and TGA-FTIR analyses. (NMT-16)

- Support Hanford processing activities with TGA-MS and TGA-FTIR analyses. (NMT-16)

The TGA/MS/FTIR analytical methods will be used to test representative materials from the complex by measuring moisture levels of these materials. The chain of custody of the materials must be documented. Moisture measurements will be done in triplicate and the results reported to within a 95\% confidence interval. The results will be given to the customer (RFETS, Hanford, SRS, LANL).

\section{SFE Support:}

- $\quad$ Complete the SFE Technical Basis Report (C-ACT)

- The SFE instrument, as stated above, will be maintained in an operation state to support 94-1 moisture measurement analysis. Other special programs will be addressed, as they are needed. (C-ACT) 
Signatures:

NMT-4 Group Leader

NMT-11 Group Leader

NMT-16 Group Leader

C-ACT Group Leader

Principal Investigator

Principal Investigator

Principal Investigator

Project Leader

Program Leader
Date

Date

Date

Date

Date

Date

Date

Date

Date 


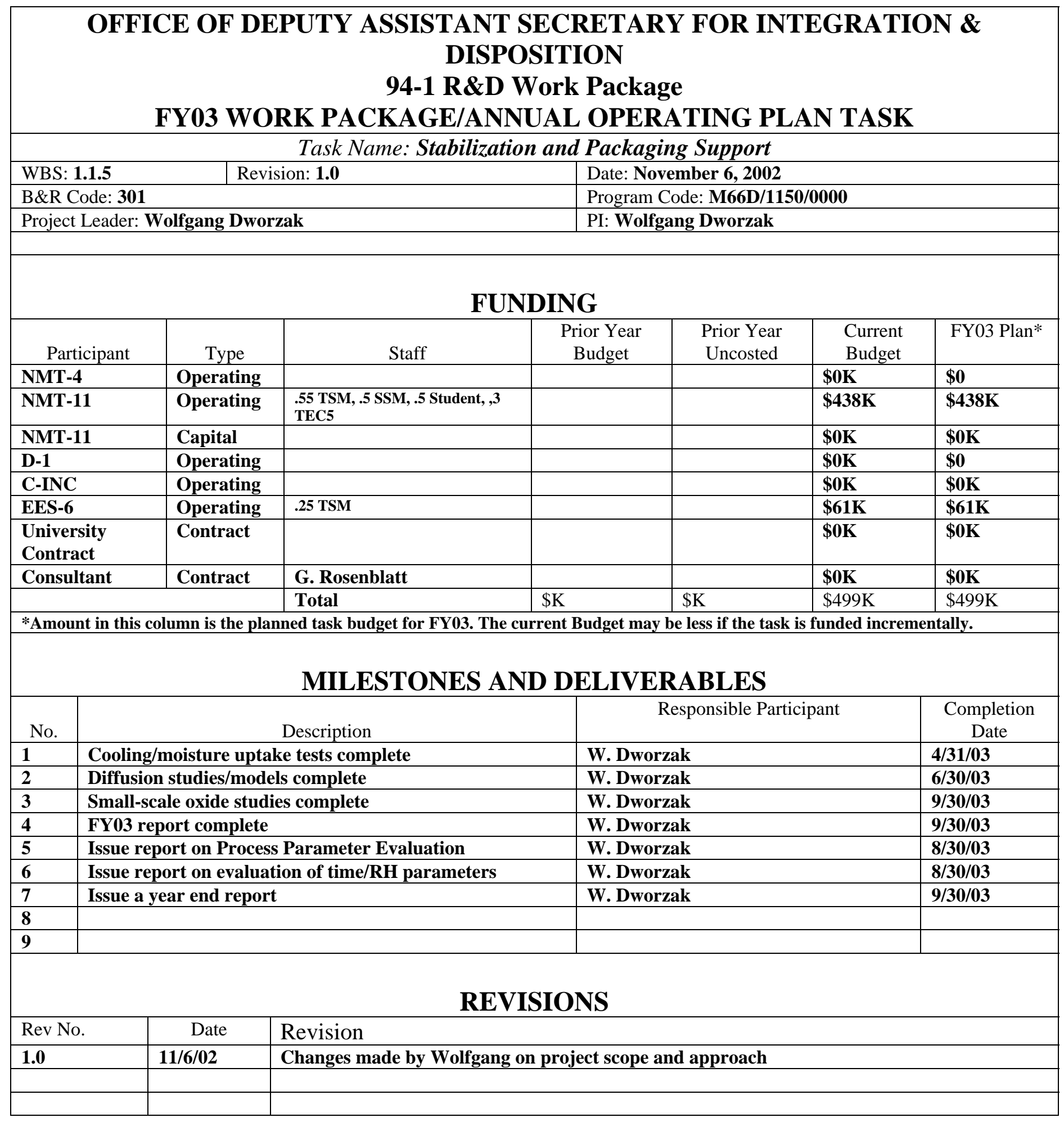




\section{WORK SCOPE}

- Complete small-scale moisture uptake studies and large-scale furnace support tests. Transfer MS to PF-3/R187.

- Complete moisture uptake, cooling studies and 3013 process support work.

- Modeling of diffusion from/to cooling oxide, general diffusion models.

- Statistics support.

Issue(s):

- Equipment and personnel are available to expeditiously evaluate unforeseen stabilization and storage issues related to current or past processing.

- Incomplete understanding of how operational parameters control moisture pick up.

- Incomplete understanding of how operational parameters affect corrosion of the furnaces during stabilization or corrosive materials that are loaded into a 3013 materials.

Scope:

This task supports the expedient resolution of unforeseen issues associated with stabilization, packaging, transportation, and storage. The experiments focus on determining the moisture uptake behavior of oxides that are proposed for long-term storage. The intent is to provide information to packaging sites that help them meet schedules and that supports creation of realistic surveillance strategies. This includes production of empirical and theoretical models that allow determination of the effects of given environments on the uptake of moisture by oxide batches during and after cooling and relate that information to the shelf life study results and 3013 container storage. Studies use non-radioactive surrogate materials to represent actual oxides in full-scale process equipment that has been fitted with the supplementary instrumentation and controls necessary for parametric testing. When practical, confirmation of results using actual plutonium oxide batches in existing process equipment in the Los Alamos plutonium facility, PF-4, will be conducted.

DOE-STD-3013-2000 requires that stored Pu Oxide contain less than 0.5\% moisture. Questions exist regarding moisture uptake after calcination, since tests on representative oxides show occasional rapid readsorption rates. It is important to understand these rates and project them to various types of oxides that are candidate for long term storage. We must know how long we have to seal the containers since this impacts process rates and the ability to use qualified processes in lieu of moisture measurement on each longterm item. We also must know how to obtain oxide samples for moisture testing that represents the moisture content of heterogeneous (impure) oxides. Both of these questions can be answered duing our planned testing.

Approach:

- Provide experimental data and technical expertise to establish stabilization process criteria specific to all sites intending to seek process qualification with focus on hard to process items.

- Develop and implement a test plan for validating process qualification requirements.

- Evaluate maximum length of time a processed sample can remain exposed to glovebox atmosphere after moisture measurement and before sealing in 3013 container.

- Evaluate the effects of salts and other known impurities during stabilization on stabilization equipment.

- Evaluate the effects of unanticipated constituents during stabilization on stabilization equipment.

- Assist in evaluating various oxide impurities with TGA analysis.

- Help the complex trouble shoot calcination and packaging problems as they occur throughout.

Calcine $(\mathrm{Pu})$ surrogate oxides containing (actual) moisture adsorbing impurities in process scale equipment. Place the process scale crucibles into a cooling chamber (while still near to the maximum temperature) and measure moisture uptake during cooling (as weight gain) in a controlled environment (cooling air rate and humidity). Perform supporting small scale tests of uptake by (pure) impurity compound. Also, perform moisture diffusion rate tests to establish diffusion coefficients for pure matrix. Analyze results to develop stochastic and predictive/mechanistic models, allowing extension to other impurities and items, which can affect the packaging process or the storage container. Finally, develop data regarding equipment corrosion and effects of corrosion products results from processing of impure oxides. 
Signatures:

NMT-11 Group Leader

EES-6 Group Leader

Principal Investigator

Project Leader

Program Leader
Date

Date

Date

Date

Date 


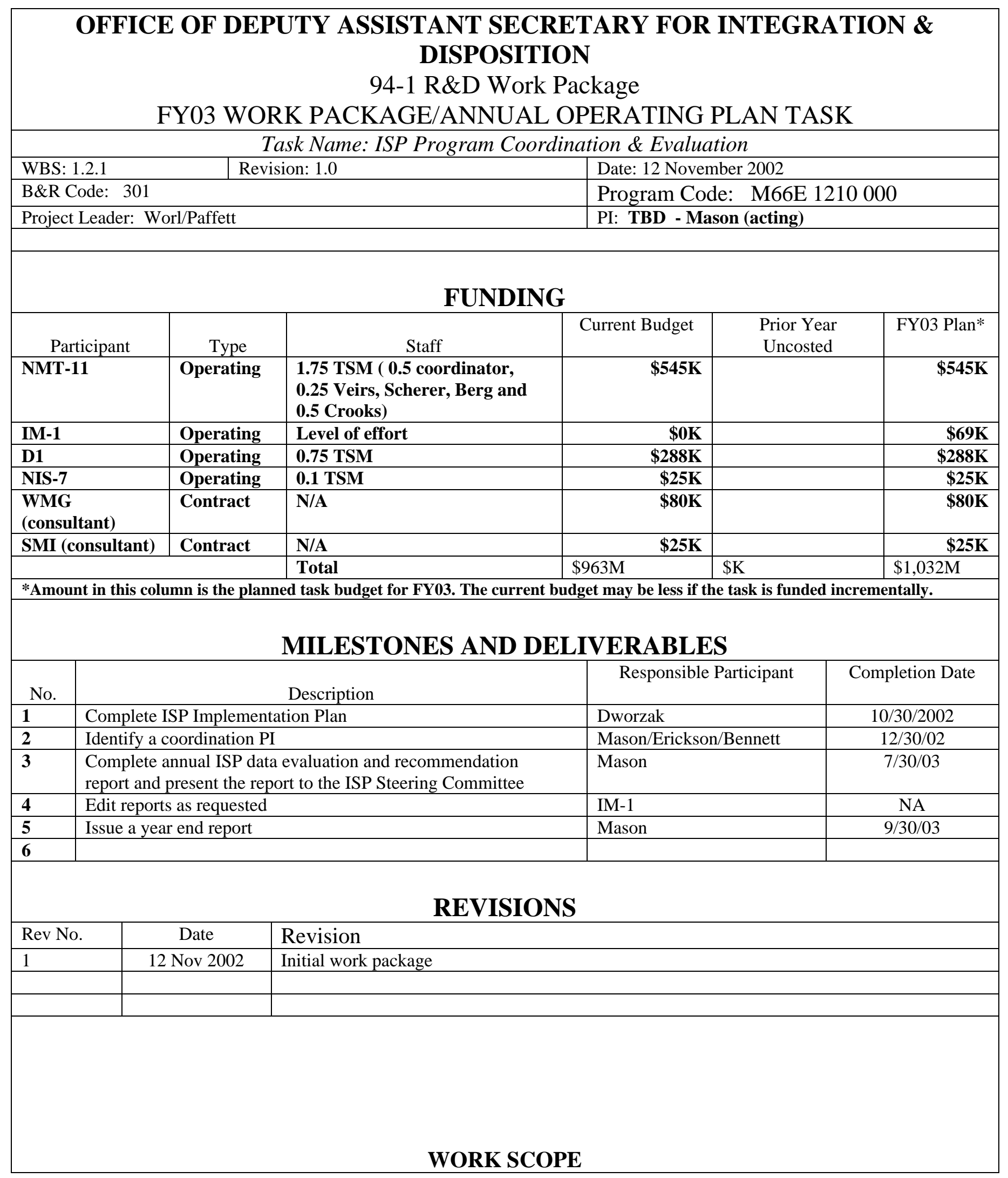


Scope:

Surveillance activities at each of the sites will continue to meet the requirements of good operation practice and to meet the requirement 6.4 of the standard. The ISP coordination team will work with each site to coordinate their surveillance activities with complex surveillance program, will coordinate collection of the appropriate data (working with the Data Collection, analysis, and reporting team) and evaluate, analyze, and report and will in turn provide this information to the DOE complex.

Issues:

1) Uncoordinated site surveillance activities will necessarily duplicate efforts and cost more money.

2) Safety issues identified at one site may not be communicated to the other sites.

3) Data gleaned in each site's stabilization, packaging, and storage efforts will not be available to other sites to assist and support their safe storage efforts.

Approach:

The following activities are planned for FY03:

- $\quad$ Continue the implementation of the Integrated Surveillance Program and support implementation of the sitespecific surveillance plans. (NMT-11)

- $\quad$ Work with sites. (All)

- $\quad$ Provide support to storage sites as necessary to resolve issues associated with implementation of surveillance programs. (All)

Evaluate stabilization, packaging, and surveillance data collected from RFETS, LANL, LLNL, and Hanford. (NMT-11)

Coordinate efforts between sites, with the MIS-WG and ISP steering committee. (D1)

Provide statistical support for experimental designs and data evaluations of stabilization support studies, TGA development, NMI development, ISP activities, etc. (D1)

Issue a white paper outlining the trade/off studies identifying the number of confirmatory samples required during processing. (D1)

Conduct a one day workshop on statistical methods for measurement/sampling uncertainties and experimental design geared specifically for MIS activities. (D1)

Provide technical support to implement integrate surveillance and stabilizations technologies. (SMI)

- $\quad$ Provide technical support to implement neutron moderation instrument development. (WMG) 
Signatures:

NMT-11 Group Leader

NIS-7 Group Leader

D-1 Group Leader

Principal Investigator

Project Leader

Program Manager
Date

Date

Date

Date

Date

Date 


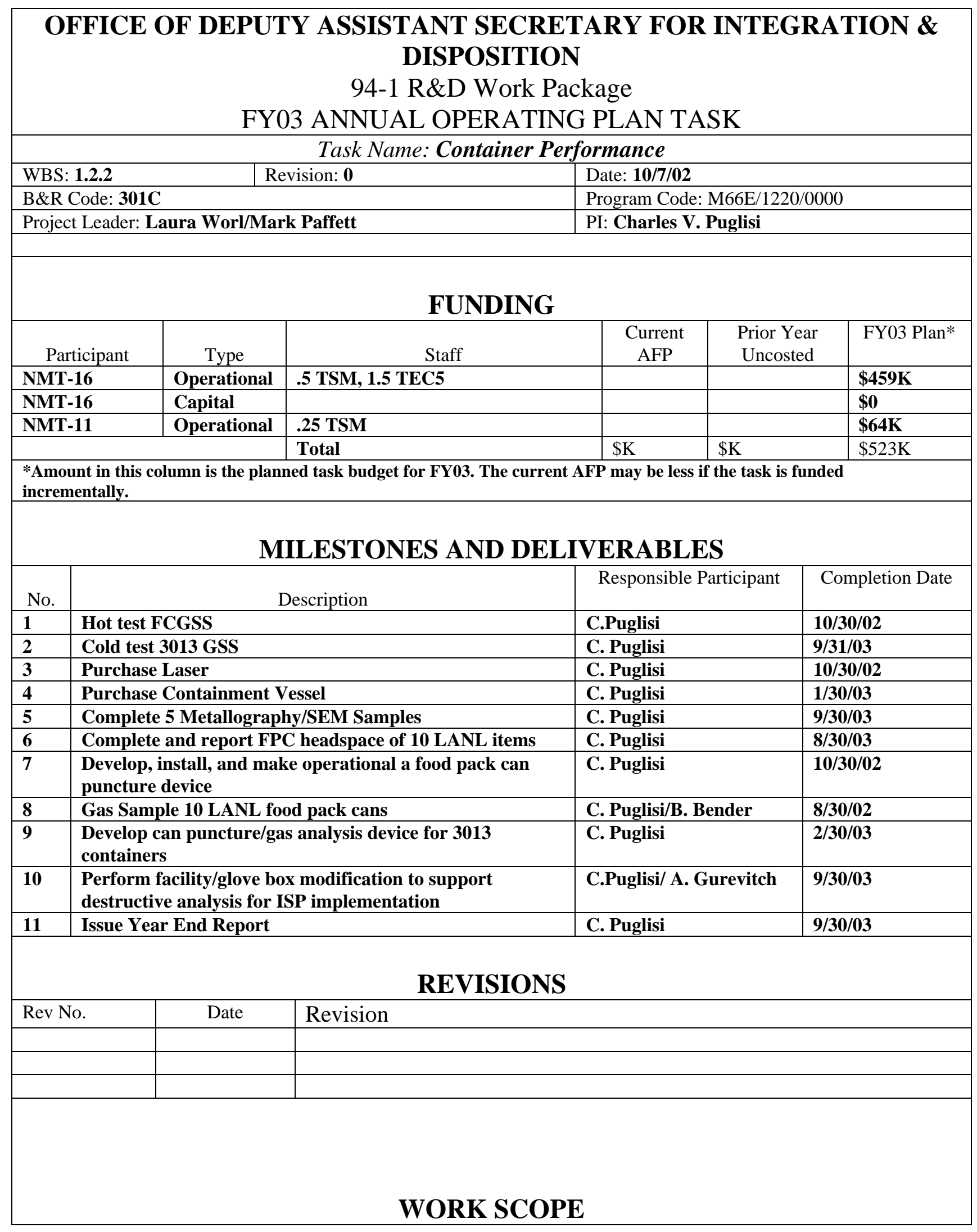


Continue design and deployment of gas sampling systems for 94-1 work.

Issue(s):

- Develop a gas sampling system for 94-1 needs.

- If a can pressurizes there is no protocol or equipment to relieve the pressure and at the same time find what gases were generated to cause the pressurization.

- Corrosion can only be evaluated by destructive examination methods thus containers must be opened to evaluate the long-term performance of the containers.

- Some containers may hold material that needs to be better characterized and tested in the shelf-life program to ensure MIS inventory and data of stored material adequately bounds expected materials and storage conditions.

Scope:

Cold test systems at CMR.

Deploy systems at TA-55.

The container performance task develops the safe storage technical basis by evaluating real containers and materials. The focus of this task is to develop and establish an analysis program and nondestructive and destructive examination (NDE and DE) capabilities at LANL required for the site wide ISP. Headspace gas composition, container condition, and material (container and stored materials) are evaluated. Non-destructive examinations will be performed on both Los Alamos containers and containers received from other sites. Destructive examination techniques will be evaluated and applied to the examination of containers sent to Los Alamos. The results from this task verify the results, analyses and safe storage predictions of the shelf-life task, the MIS characterization task, and special topic studies.

\section{Approach:}

- Continue to develop new engineering techniques for high pressure/flammable gas sampling of 3013 containers.

- The focus of this task is to develop and establish an analysis program and nondestructive and destructive examination (NDE and DE) capabilities at LANL required for the site wide ISP.

- A can punch will be deployed to relieve pressure and determine the headspace gas composition in any of the proposed 3013 container configurations.

- Non-destructive examinations will be performed on both Los Alamos containers and containers received from other sites.

- $\quad \mathrm{NDE}$ techniques will be evaluated and improvements developed or suggested as required.

- Destructive examination techniques will be evaluated and applied to the examination of containers sent to Los Alamos. The necessary metallographic capabilities and sampling protocols will be developed.

- The headspace gas of 3013 containers will be sampled and pressures determined. Most significantly, protocol and equipment to relieve pressure in a 3013 container in the event that one may be pressurized will be established. 
Signatures:

NMT-11 Group Leader

NMT-16 Group Leader

Principal Investigator

Project Leader

Program Leader
Date

Date

Date

Date

Date 


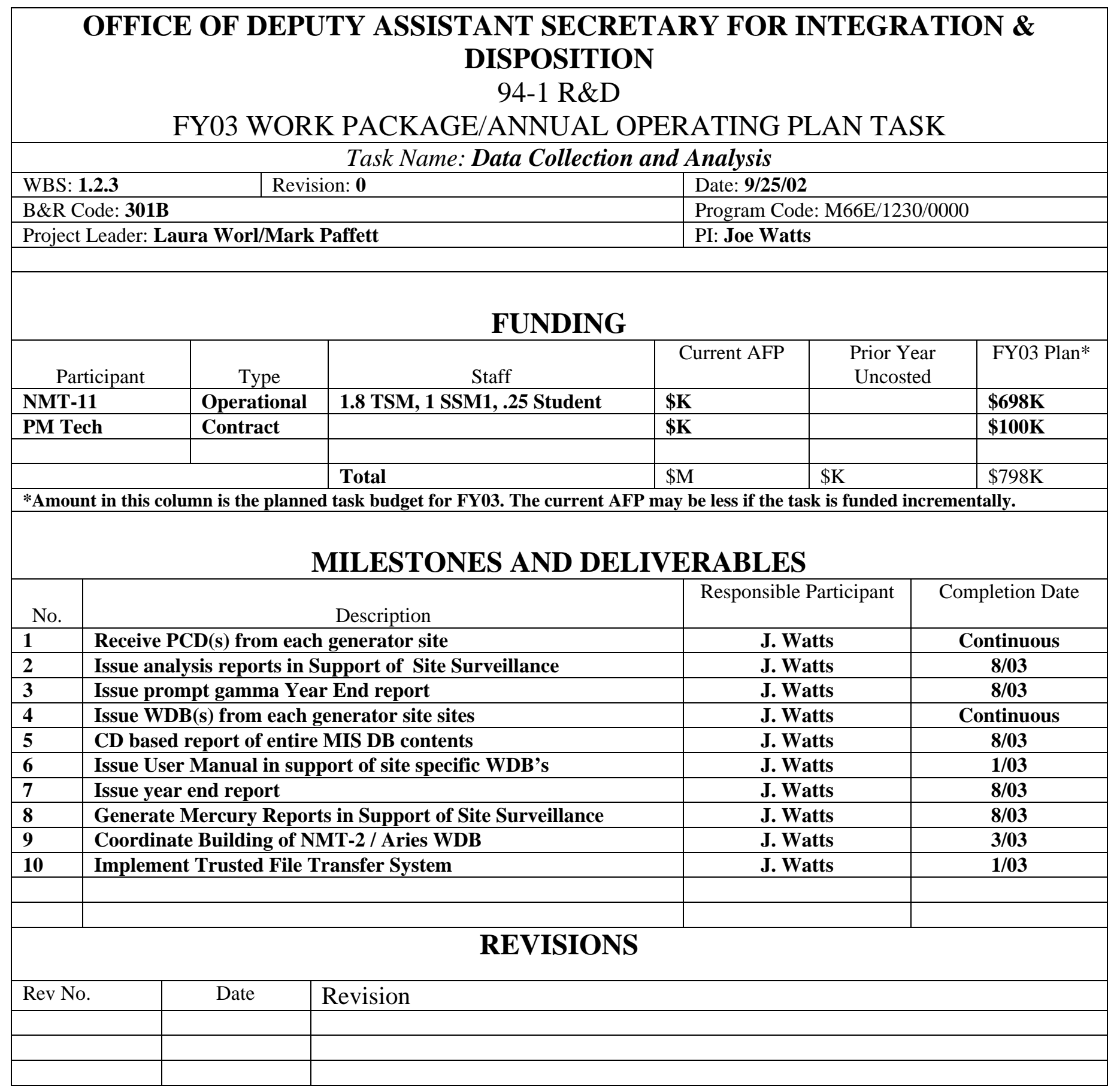




\section{WORK SCOPE}

The Data Collection and Analysis function is the vital coordinating link ensuring that all of the shipping and receiving sites adhere to the technical data requirements necessitated by the 3013 Standard the Integrated Surveillance Program (ISP) and any specific Shipper-Receiver Agreements (SRA). Technical Leadership Coordination and Analysis is performed in coordinating the flow of the data from the sites. Often we provide the front line technical leadership associated with technical compliance when shippers are faced with impending changes and resulting data collection issues.

Issue(s):

- For an integrated (complex wide) surveillance program to work information from the sites must be available to analyze, compare and predict performance.

- Generator site production issues have impacted transmittal of data to Receiver site/ LANL for inclusion in the Integrated Surveillance Plan (ISP).

- Hanford has requested

Scope:

Data collection, analysis, and reporting task is key to the integrated surveillance program. The product of this task is three databases coordinated through LANL and distributed throughout the complex. The database collects data from and supports Rocky Flats, Savannah River, Hanford, Lawrence Livermore and Los Alamos. Databases associated with the ISP include: 1) The complex-wide integrated surveillance plan database which coordinates the core required data fields detailed in the integrated surveillance plan (ISP) and any additional items specific to shipper-receiver agreements (MOA) between all of the shipping sites and SRS, including items generated at SRS. 2) Hanford efforts, plus is a compilation of items originating from Hanford, Rocky Flats and Los Alamos and any associated collected scientific reports and 3) The Site Specific database which is repository for shelf-life studies funded through the 94-1 R\&D program surveillance results from the 94-1 R\&D efforts as well as information from the site specific surveillance program plus DP, 94-1 DP, ARIES MD, and Fuel Studies MD, coordinating the core required data fields detailed in the Integrated Surveillance Plan (ISP) and any additional items specific to the Shipper-Receiver agreement (MOA) between LANL and SRS as well as any relevant readily available information as referenced in the ISP.

\section{Approach:}

The true power of the Complex-Wide database is the ability to sort across the collected data from all of the sites to match-up container profiles as a result of storage failures, failures or conditions conducive to failure predicted by models, the small and large can shelf-life studies, or any other plausible source.

- $\quad$ Publish schedule for distribution of Site-Specific databases to sites

- $\quad$ Provide Site-Specific databases to sites

- $\quad$ Work with SRS/Hanford to point out site specific anomalies to help facilitate MOA's

- $\quad$ Work with SRS/Hanford to help establish data delivery schedules Complex-Wide

- $\quad$ Provide Training Across Complex on Site-Specific databases

- $\quad$ Serve as the technical lead for data base issues in response to sites

- $\quad$ Using Trusted File Transfer System create open access to Complex-Wide ISP Database

Analyze and publish data from generation sites with specific emphasis on failure profiles

- $\quad$ Integrate Process Qualification Requirements to assure fidelity of data

- $\quad$ Receive Rocky Flats Site Specific Database

- $\quad$ Continue PCD assistance to RFETS: including Scan Line and Database Support

- $\quad$ Provide Working Databases/ Product Certification Databases and Support including Software User Manual to SRS, LLNL, Hanford, and LANL (already established at RFETS)

Grow Integrated Surveillance Database by adding to the RFETS data, additional data from SRS, LLNL, Hanford, and LANL

Share with MIS working group data related to all items, "representedness", and have supporting documentation for all data in the database available electronically 
Produce and distribute software for visualization of Prompt Gamma files already available via the MIS website Continue to maintain and update MIS website including work in progress, authorizing documents and new item observations

Work with SRS and Los Alamos to point out site specific anomalies unique to Los Alamos processing, facilitating

Work with SRS to help establish Los Alamos data delivery schedule

Capture data yielded from Small and Large can studies

Creation of secure Web Interface to PF-4

Initiate internal review of data

Create methodology for promotion out to world

Capture data yielded from Destructive Analysis studies

Monitor pressure indicating devices

Capture radiographs

Facilitate analytical review and visualization of items for SRS

Integrate Process Qualification Requirements to assure fidelity of data

Update backlog of MIS data obtained from new or reprocessed items

Utilize MASS to obtain new data for characterization and shipper-receiver data

Utilize LIMS to obtain new data for chemical analyses

Using Process data certified by the Process Qualification Plan post new data to web site for review by MIS Working Group

Create Process Flow Charts for inclusion of data to Complex-Wide Surveillance database

Validate Process Flow Charts using MASS data

Create Standard for Prompt Gamma using Chemical Analyses and Prompt Gamma findings

Update photo-catalog for new or backlogged items 
Signatures:

NMT-11 Group Leader

Principal Investigator

Project Leader

Program Manager
Date

Date

Date

Date 


\title{
OFFICE OF DEPUTY ASSISTANT SECRETARY FOR INTEGRATION \& DISPOSITION
}

\author{
94-1 R\&D Work Package
}

FY03 ANNUAL OPERATING PLAN TASK

Task Name: Shelf Life Studies: Large and Small Scale

\begin{tabular}{|c|c|}
\hline \multirow{2}{*}{$\frac{\text { BS: } 1.3 .3}{\mathrm{LR} \text { Code: } 301}$} & Date: $11 / 14 / 02$ \\
\hline & Program Code: M66E 12400000 \\
\hline ject Leader: Laura Worl & PI: Laura Worl \\
\hline
\end{tabular}

\section{FUNDING}

\begin{tabular}{l|l|l|l|r|r|r|}
\hline \multicolumn{1}{|c|}{ Participant } & \multicolumn{1}{|c|}{$\begin{array}{c}\text { STAFF- } \\
\text { Current budget }\end{array}$} & $\begin{array}{c}\text { Prior Year } \\
\text { Budget }\end{array}$ & $\begin{array}{c}\text { Prior Year } \\
\text { Uncosted }\end{array}$ & $\begin{array}{c}\text { Current } \\
\text { Budget }\end{array}$ & FY03 Plan* \\
\hline MT-11 & Operating & $\mathbf{3 . 8 5}$ FTE & & & $\mathbf{1 1 6 9}$ & $\mathbf{1 4 0 0}$ \\
\hline MT-2 & Operating & $\mathbf{0 . 2 2}$ FTE & & & $\mathbf{5 0}$ & $\mathbf{7 5}$ \\
\hline PCS & Operating & $\mathbf{1 . 0}$ FTE & & & $\mathbf{3 0 0}$ & $\mathbf{3 0 0}$ \\
\hline SA-AET & Operating & $\mathbf{0 . 4 0 ~ F T E ~}$ & & & $1669 \$ \mathrm{~K}$ & $1975 \$ \mathrm{~K}$ \\
\hline tal & & & & $\mathbf{1 5 0}$ \\
\hline
\end{tabular}

mount in this column is the proposed budget for FY03. It would include loading 2 additional large containers and up to 40 all scale containers.

MILESTONES AND DELIVERABLES- Reflect Current Budget of \$1669K

\begin{tabular}{l|l|c|c|}
\hline \multicolumn{1}{|c|}{ Description } & Responsible Participant & Completion Date \\
\hline Quarterly Reports (3) & $\begin{array}{c}\text { NMT-11, C-PCS, } \\
\text { ESA-AET }\end{array}$ & ongoing \\
\hline Large Scale Study & & \\
\hline $\begin{array}{l}\text { Hazard Analysis for Large Scale Study Completed } \\
\text { by NMT and submitted to OAB }\end{array}$ & NMT-11, NMT-14 & $\mathbf{1 1 / 6 / 0 2}$ \\
\hline Readiness Assessment & $\begin{array}{c}\text { NMT-11, C-PCS, } \\
\text { NMT-14, DOE- }\end{array}$ & $\mathbf{1 / 3 0 / 0 3}$ \\
& LAAO & \\
\hline $\begin{array}{l}\text { Authorization Basis to proceed from NMT and DOE } \\
\text { obtained }\end{array}$ & NMT-11, NMT-14 & $\mathbf{2 / 2 5 / 0 3}$ \\
\hline Load second oxide container for full scale study & NMT-11, NMT-2 & $\mathbf{2 / 2 5 / 0 3}$ \\
\hline Load third oxide container for full scale study & NMT-11, NMT-2 & $\mathbf{5 / 5 / 0 3}$ \\
\hline $\begin{array}{l}\text { Mid Year report to MIS Working Group on } \\
\text { large scale containers }\end{array}$ & NMT-11, C-PCS & $\mathbf{5 / 7 / 0 3}$ \\
\hline Load fourth oxide container for full scale study & NMT-11, NMT-2 & $\mathbf{7 / 1 4 / 0 3}$ \\
\hline Load fifth oxide container for full scale study & NMT-11, NMT-2 & $\mathbf{1 0 / 1 / 0 3}$ \\
\hline & $\begin{array}{l}\text { Small Scale Study } \\
\text { PF-4equipment testing complete including } \\
\text { calibration gas samples }\end{array}$ & NMT-11, C-PCS, & $\mathbf{1 2 / 2 4 / 0 3}$ \\
\hline Authorization Basis obtained & NMT-AET & $\mathbf{2 / 1 2 / 0 3}$ \\
\hline Load first 5 containers & NMT-11, C-PCS & $\mathbf{2 / 1 9 / 0 3}$ \\
\hline Load second 5 containers & NMT-11, C-PCS & $\mathbf{4 / 2 / 0 3}$ \\
\hline & & \\
\hline
\end{tabular}




\begin{tabular}{l|l|c|}
\hline $\begin{array}{l}\text { Mid Year report to MIS Working Group on } \\
\text { first 10 containers }\end{array}$ & NMT-11, C-PCS & $\mathbf{5 / 7 / 0 3}$ \\
\hline $\begin{array}{l}\text { Load additional small-scale samples that } \\
\text { contain representative DOE site-wide oxide } \\
\text { including sample blanks and replications based } \\
\text { on MIS Working Group requests and Small } \\
\text { Scale Sample Loading Plan. }\end{array}$ & NMT-11, C-PCS & $\mathbf{8 / 2 0 / 0 3}$ \\
\hline $\begin{array}{l}\text { Collect, interpret and report data of large and } \\
\text { small-scale surveillance containers - input } \\
\text { information into a final year -end report }\end{array}$ & $\begin{array}{c}\text { NMT-11, C-PCS, } \\
\text { ESA-AET }\end{array}$ & $\mathbf{1 0 / 2 8 / 0 3}$ \\
\hline
\end{tabular}

REVISIONS

\begin{tabular}{l|c|l}
\hline v No. & Date & Revision \\
\hline & $6 / 28 / 2002$ & MIS Small and Large Sample Surveillance in old format - budget \$1925K \\
\hline & $9 / 23 / 02$ & Revised budget and subsequent reduction in work scope from \$1750K to \$1669K \\
\hline & $10 / 31 / 02$ & Modified allocations (\$300K to C-PCS versus \$180K) \\
\hline & $11 / 14 / 02$ & $\begin{array}{l}\text { Modified work scope due to increased taxes from NMT DO, to only loading 3 } \\
\text { additional large scale container in FY2003. }\end{array}$ \\
\hline
\end{tabular}

\section{WORK SCOPE}

\section{rpose:}

e purpose of this project is to assist in the establishment of parameters for safe storage of plutonium bearing materials der the DOE packaging and storage standard (DOE-STD-3013) for Materials Disposition, and DOE sites (SRS, 'ETS, Hanford, LANL, and LLNL).

ope:

though the 3013 container provides for a robust storage system, its safety performance has not been demonstrated. To sure container failures do not occur in long-term storage, this work will conduct a matrix of parametric studies to ablish the boundaries under which a failure may occur. A potential failure mechanism associated with long-term rage of stabilized plutonium materials in 3013 containers is a failure from container pressurization as a result of gas leration. Further research in this area is required to provide better definition of gas generation failure mechanisms to sure safe long-term storage of these materials. This project will monitor gases in full-scale containers with oxide tterials and in small-scale containers with samples taken from represented materials actually being stored. The smallle containers allow more sample types and conditions to be studied. Both types of containers will be loaded with ide materials and monitored over time. For the large-scale study, baseline plutonium oxides, oxides exposed to highmidity atmospheres, and oxides containing chloride salt impurities are planned. Samples from materials packaged for rage will also be included. The shelf-life surveillance will provide the DOE complex with mechanisms for gathering, erpreting, and reporting experimental storage data on plutonium-bearing materials. The information will support DOE ındard, the DOE Integrated Surveillance Plan and the Site Specific Surveillance activities.

'proach:

e LANL based shelf-life surveillance project has two parallel studies. Many small (10-g) samples are monitored for atively short time periods, and a limited number of large samples equivalent in size to the 3013 storage can capacity will monitored for long periods of time. The small samples will allow a database of many material types prepared according various site-specific packaging methods to be compiled. Large-scale studies will give the behavior of a limited number samples in the precise geometry and environment in which the material will be stored. Comparison between the two nple types will determine the degree of confidence in small sample experiments and fundamental measurements in :dicting the long-term behavior of real materials.

e instrumented storage containers mimic the inner storage can specified in the 3013 standard at both large- and smalllle capacities (2.3 liter and 0.0045 liter, respectively). The containers are designed to maintain the volume to material sss ratio while allowing the gas composition and pressure to be monitored over time. The large-scale cans are 
trumented with a Raman fiber-optic probe, a gas chromatography (GC) / mass spectrometer (MS) sampling port, an sustic resonance chamber, two corrosion monitors, and pressure and temperature sensors. Data collection for the largetle containers is automated in order to reduce worker exposure. The small-scale containers are designed with a croliter gas-sampling capability and pressure and temperature sensors. These containers will be stored in a heated array order to reproduce the increased temperatures arising from radioactive self-heating.

ide materials representing inventories destined for long-term storage throughout the DOE complex will be monitored. e matrices of materials for the large and small-scale experiments are approved by the MIS Working Group. Thirtyee items from Hanford and Rocky Flats Environmental Technology Site have been evaluated by the LANL MIS jject. [Mason 1999] Residuals from these evaluated items make up the surveillance items to date for the small-scale terials. In the future, materials may be drawn from the Los Alamos inventory or from other sites to assure that these rentories are represented for safe storage under the 3013 standard. The materials will be characterized as necessary or to packaging in the large- or small-scale containers. Characterization data will include density, isotopics, particle e, specific surface area, moisture content, wattage, and chemical composition. 
Signatures:

NMT-11 Group Leader

C-PCS Group Leader

NMT-2 Group Leader

ESA-AET Group Leader

Principal Investigator

Project Leader

Program Manager
Date

Date

Date

Date

Date

Date

Date 


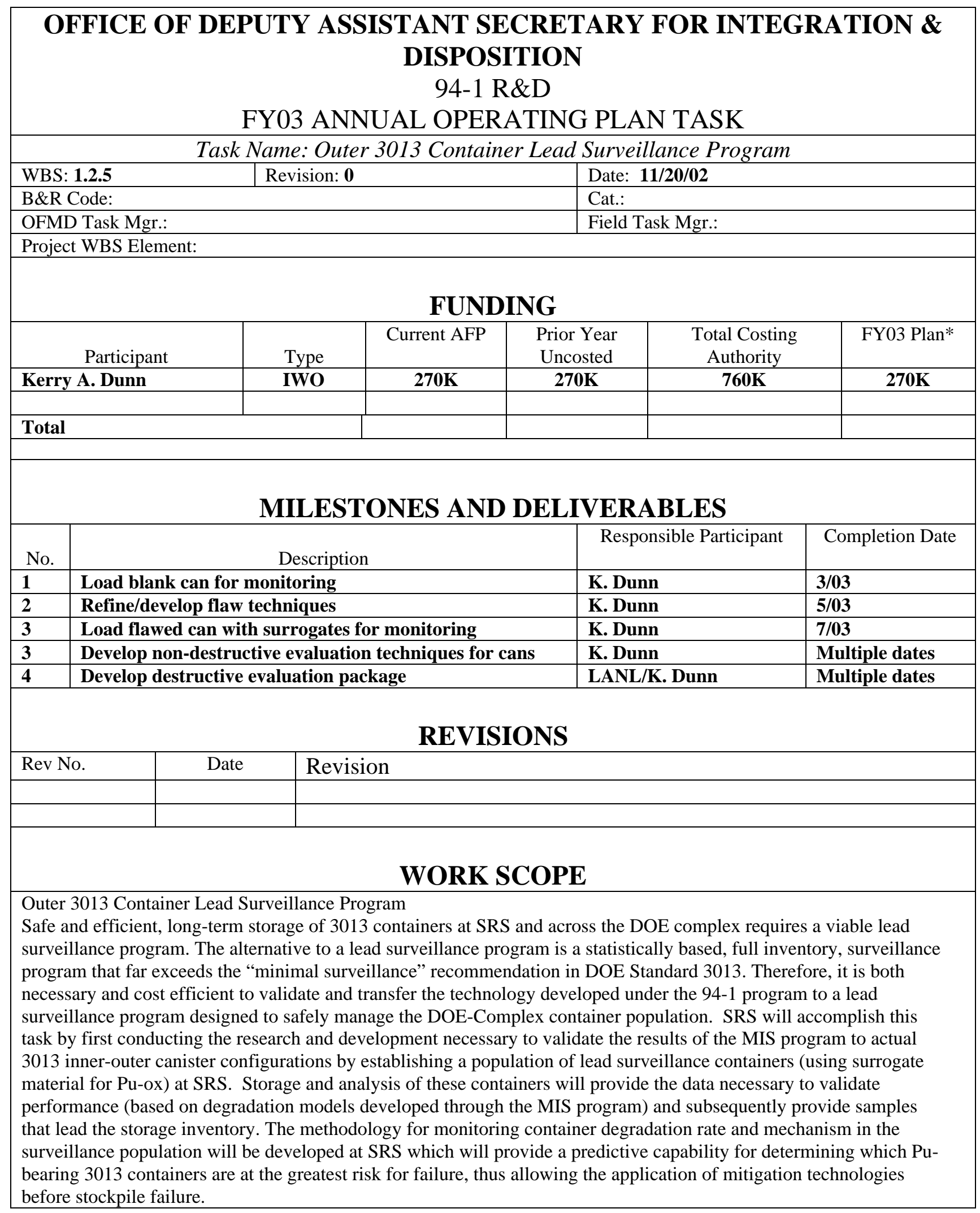


Purpose:

To develop 3013 packages loaded with surrogate materials to lead the storage stockpile in terms of degradation of the package. Monitor the degradation of the packages over time both non-destructively and destructively. Develop techniques and methodology that will assist storage sites in identifying suspect packages.

Technical Approach:

Materials Characterization In order to access the degree of degradation in surveillance containers it will be necessary to establish a baseline characterization of typical production materials. This characterization will include optical metallography, scanning electron microscopy, and tensile properties. It is anticipated that these methods will also be used in the destructive evaluation of the surveillance containers.

Weld Characterization Optical metallography, scanning electron microscopy, and tensile testing will also be used to establish the baseline properties of typical TIG and Laser welds as well as the heat affect zone.

Lead Surveillance Containers 3013 outer containers that comply with the DOE-STD-3013 standard will be procured. A combination of laser welded and TIG welded outer 3013 containers will be used for the lead surveillance program. High residual stress have been identified for both the TIG welded and laser welded containers. These areas of high residual stresses are expected to be the most susceptible to stress corrosion cracking. To ensure the continuing relevance of the experimental parameters used in the proposed investigation, interfaces with the ongoing MIS and ISP programs will provide information regarding:

a) quantity of moisture in the packages

b) salt content

c) radiolytic gas generation and pressurization of stored Pu packages

d) metallurgical and environmental variables influencing corrosion related degradation processes

Inner Surveillance Containers Inner containers will be fabricated from 304 stainless steel. The inner will be designed to maximize the available volume in the outer container and incorporate a heater well to control temperature. Surrogate materials will be loaded into the inner container and then welded closed. The inner container will contain a simulated flaw(s) (stress corrosion crack or a pit) to mock a failed inner container. This flaw will be positioned in the inner can to interface with the most susceptible region of the outer can. Some of the flaws will be through wall so that the integrity of the inner container will be compromised.

Methodology for Evaluating Surveillance Containers It will be desirable to evaluate the surveillance containers by both destructive and non-destructive means. Non-destructive methods may include but are not limited to visual, radiography, digital radiography, lid deflection measurements and remote sensing devices. These non-destructive tests will be conducted throughout the storage life of the containers, approximately every six months. Destructive evaluation of the surveillance containers with optical metallography, scanning electron microscopy, and tensile tests will be done at selected intervals. Prior to the destructive analysis, a methodology to maximize the amount of data gathered from these containers will be established. This program is intended to be a living program that will support any number of different designs of 3013 containers that will be used for storage at SRS and other sites.

Application of Results Results from this study will give SRS a predictive capability for determining which Pu-bearing 3013 containers are at the greatest risk for failure. To accomplish this it will be necessary to develop a methodology for using acquired data to predict most vulnerable 3013 containers in SRS population. In addition, program activities and emerging results will be routinely discussed with personnel working in the MIS and ISP arenas to maximize productivity and minimize investigative duplication.

Documentation The SRS site specific Pu package surveillance plan discusses the overall surveillance activities necessary to ensure the safe storage of Pu packages in the K-Area Materials Storage (KAMS) facility. This plan outlines the need for operational surveillance activities as well as the life extension surveillance activities. As part of the lead surveillance program being established by SRTC, a detailed matrix outlining the 3013 container testing program has been drafted and will be further refined as necessary. In this matrix, the initial numbers of 3013 containers and the conditions under which they will be fabricated and tested will be defined. The storage conditions for each container and proposed schedule to analyze the containers will be provided in this detailed matrix. In addition the status of the surveillance program will be provided to DOE periodically. 


\begin{tabular}{|c|c|c|c|c|c|c|c|}
\hline \multicolumn{8}{|c|}{$\begin{array}{c}\text { OFFICE OF DEPUTY ASSISTANT SECRETARY FOR INTEGRATION \& } \\
\text { DISPOSITION } \\
\text { 94-1 R\&D Work Package } \\
\text { FY03 WORK PACKAGE/ANNUAL OPERATING PLAN TASK }\end{array}$} \\
\hline \multicolumn{8}{|c|}{ Task Name: Container and Material Interactions } \\
\hline \multicolumn{4}{|c|}{ Revision: 3.0} & \multicolumn{4}{|c|}{ Date: 4 November 2002} \\
\hline \multicolumn{4}{|c|}{ B\&R Code: } & \multicolumn{4}{|c|}{ Program Code: M66E/1270/0000 } \\
\hline \multicolumn{4}{|c|}{ Project Leader: Worl/Paffett } & \multicolumn{4}{|c|}{ PI: Lillard } \\
\hline \multicolumn{8}{|c|}{ FUNDING } \\
\hline \multicolumn{2}{|c|}{ Participant } & Type & Staff & $\begin{array}{c}\text { Current } \\
\text { FP }\end{array}$ & \multicolumn{2}{|c|}{$\begin{array}{l}\text { Prior Year } \\
\text { Uncosted }\end{array}$} & FY03 Plan* \\
\hline \multicolumn{2}{|c|}{ MST-6 } & Operating & $\sim 1$ TSM & $\$ 300 K$ & & & $\$ 300$ \\
\hline \multicolumn{2}{|c|}{ NMT-15 } & Operating & 0.3 TSM & $\$ 75 K$ & & & $\$ 75 K$ \\
\hline & & & & $\$ K$ & & & \$K \\
\hline & & & & $\$ \mathbf{K}$ & & & $\$ 0$ \\
\hline & & & & $\$ K$ & & & $\$ \mathbf{K}$ \\
\hline & & & Total & $\$ 375 \mathrm{M}$ & $\$ 3375 \mathrm{~K}$ & & $\$ 375 \mathrm{~K}$ \\
\hline \multicolumn{8}{|c|}{$\begin{array}{l}\text { *Amount in this column is the planned task budget for FY03. The current Funding Plan (FP) may be less if the task is funded } \\
\text { incrementally. }\end{array}$} \\
\hline \multicolumn{8}{|c|}{ MILESTONES AND DELIVERABLES } \\
\hline No. & \multicolumn{3}{|c|}{ Description } & \multicolumn{2}{|c|}{ Responsible Participant } & \multicolumn{2}{|c|}{ Completion Date } \\
\hline 1 & \multicolumn{3}{|c|}{ Issue report on methodologies and literature reviews } & \multicolumn{2}{|l|}{ Lillard } & \multicolumn{2}{|c|}{ 12/15/02 } \\
\hline 2 & \multicolumn{3}{|c|}{ Finalize experimental Plan } & \multicolumn{2}{|l|}{ Lillard } & \multicolumn{2}{|c|}{ 1/15/03 } \\
\hline 3 & \multicolumn{3}{|c|}{$\begin{array}{l}\text { Complete tests to develop stress data for stainless steel } 316 \text { and } \\
\text { weld zone as a function of environment }\end{array}$} & Lillard & & $7 / 1$ & \\
\hline 4 & Suppo & ensile testing & fforts & Kolman & & $9 / 3$ & \\
\hline 5 & $\begin{array}{l}\text { Issue } \\
\text { scale c }\end{array}$ & $\begin{array}{l}\text { t on the per } \\
\text { iners }\end{array}$ & rmance of corrosion sensors in the Full & Chavarri & & $8 / 3$ & \\
\hline 6 & End-o & r report on & CC data & Lillard/K & & $9 / 1$ & \\
\hline 7 & & & & & & & \\
\hline 8 & & & & & & & \\
\hline 9 & & & & & & & \\
\hline & & & REVISIONS & & & & \\
\hline $\operatorname{Rev~I}$ & & Date & Revision & & & & \\
\hline 1.0 & & 9.15 .02 & Revised milestones & & & & \\
\hline 2.0 & & 10.29 .02 & by Lillard cost plan for FY03, remove & RTC specific & separate & & \\
\hline 3.0 & & 10.31.02 & By Richard Mason & & & & \\
\hline
\end{tabular}




\section{WORK SCOPE}

Container and Materials Interactions Task Issues:

Although the 3013 container has been designed to minimize corrosion related failure, the risk associated with a corrosion failure during the fifty year storage of stabilized plutonium-bearing materials is not known. Observations of material performance to date have been anecdotal. The goal of the 94-1 Core Technology Corrosion Program has been to identify the probability and associated risk (if a finite probability exists) that may be attributed to corrosion related failure mechanisms of the 3013 container during its projected fifty year lifetime.

Issues:

- $\quad$ Little is known about the properties and behavior of various processing salts inside stainless steel containers at expected storage conditions at KAMS.

Given the high water sorption capacity of some salts at low relative humidities, as well as their potential to be sources for radiolytically produced corrosives such as $\mathrm{HCl}$, understanding the form, distribution, and deliquescent properties is critical for 3013 stabilization and long term storage of these materials in KAMS.

Although the 3013 container has been designed to minimize corrosion related failure, the risk associated with a corrosion failure during the fifty-year storage of stabilized plutonium-bearing materials is not known. Observations of material performance to date have been anecdotal.

Scope:

A research based methodology has been developed. Undertaking this work early on as a research program establishes baseline life expectancies were none currently exists. This baseline provides the basis for analyzing future surveillance data and the necessary qualification of container design, for example, the 9975 SAFKEG certificate of transportation.

Approach:

3013 container materials and their welds will be exposed to stress, ionizing radiation, elevated temperatures, embrittling agents (e.g., gallium and plutonium), halide-containing compounds (e.g. $\mathrm{Cl}^{-} / \mathrm{F}^{-}$), and moisture. All of these environmental conditions have been shown to be deleterious to material integrity under certain conditions. In light of 3013 storage environmental conditions, the four most probable failure modes for the 3013 container are: localized corrosion, stress corrosion cracking (SCC), embrittlement(liquid metal embrittlement, LME, and Ga induced embrittlement), and radiation assisted corrosion. During this fiscal year we will review the literature to evaluate the potential of materials in corroding stainless steel in the 3013 storage environment, develop an experimental plan and evaluate corrosion at welds as a function of stress and environment.

- $\quad$ Evaluate stress/environment relationship of 316 stainless steel in projected storage conditions and projected materials of the 3013 package system. (MST-6)

Support the complex to solve corrosion related issues. (MST-6)

Support operation of the test equipment. (NMT-15)

Support operation, collect data, evaluate data, and report performance of corrosion sensors in full-scale containers. (NMT-15 and MST-6) 
Signatures:

MST-6 Group Leader

NMT-15 Group Leader

Principal Investigator

Project Leader

Program Leader
Date

Date

Date

Date

Date 


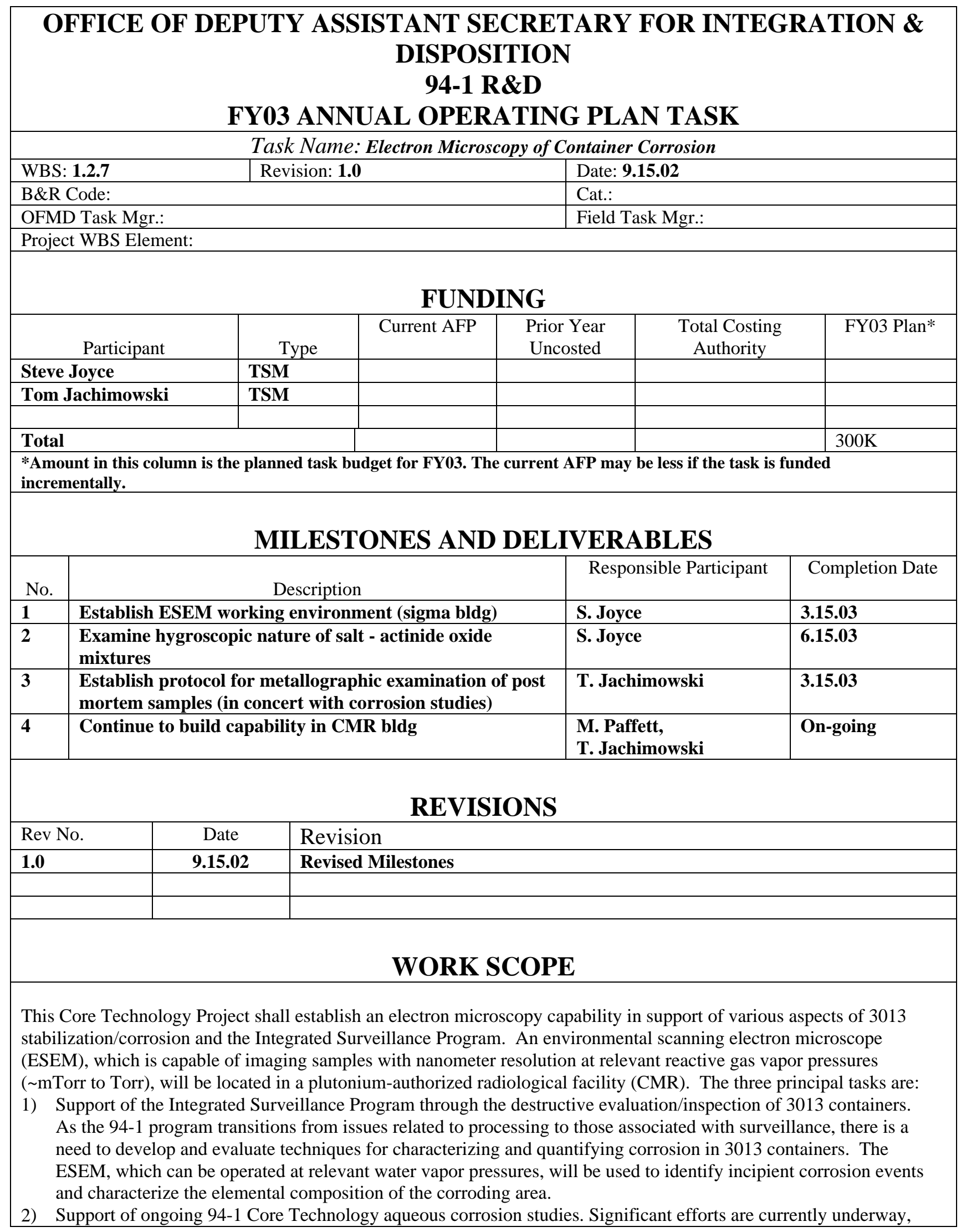


and are anticipated to continue, in determining the fundamental aspects of corrosion in the 3013 environment. The ESEM is ideally suited for examining the morphological and elemental characteristics of corrosion pits in stainless steel.

3) Studies of the morphological and deliquescent properties of various processing salts and salt/oxide mixtures in support of 3013 stabilization. While gas generation issues associated with pure $\mathrm{PuO} 2$ are reasonably well understood, little is known about the properties of the various processing salts that could remain in the container. Given the high water sorption capacity of these salts at low relative humidities, as well as their potential to be sources for radiolytically produced corrosives such as $\mathrm{HCl}$, understanding the form, distribution, and deliquescent properties is critical for 3013 stabilization. Particular emphasis will be placed on the deliquescent and dehydration properties of salt mixtures and salt/oxide mixtures as previous studies have shown that simple associative can not often be applied.

Purpose: To establish an integrated environmental SEM capability for utilization in assessing in-situ corrosion characteristics of 3013 materials in environments relevant to 3013 can interiors and to address and answer fundamental and programmatic questions concerning moisture interactions in and on complex plutonium bearing solids.

Scope: An environmental SEM is an instrument capable of imaging solids and characterizing solid surfaces in the presence a significant water vapor. This capability, unique among solid characterization techniques, shall be established to assist in interrogating solid materials that have been destructively sampled from MIS and ISP container samples. Furthermore, this capability is sought to assist in addressing deliquescence and surface morphological questions arising from salt mixtures with plutonium bearing materials possessing significant surface areas $\left(>2 \mathrm{~m}^{2} / \mathrm{gm}\right)$ and for examining corroding interfaces at relevant partial pressures of water.

Approach: We propose to establish this capability in the CMR building or work with similar equipment available in the Sigma Building where cleared laboratory space is available and the ability of sample and interrogate actinide contaminated samples is feasible. For maximal utility we shall operate this capability in concert with both 94-1 researchers engaged in corrosion studies, ISP programmatic analysis needs involving destructive metallographic analysis of 3013 container materials (both LANL and SRS), and 94-1 research addressing the synergistic effects of salt components mixed with plutonium bearing solids. This capability shall be assembled and operated in wing 3 or 7 of the CMR facility or in facilities available in the Sigma Building and shall be capable of examining actinide-contaminated samples. 


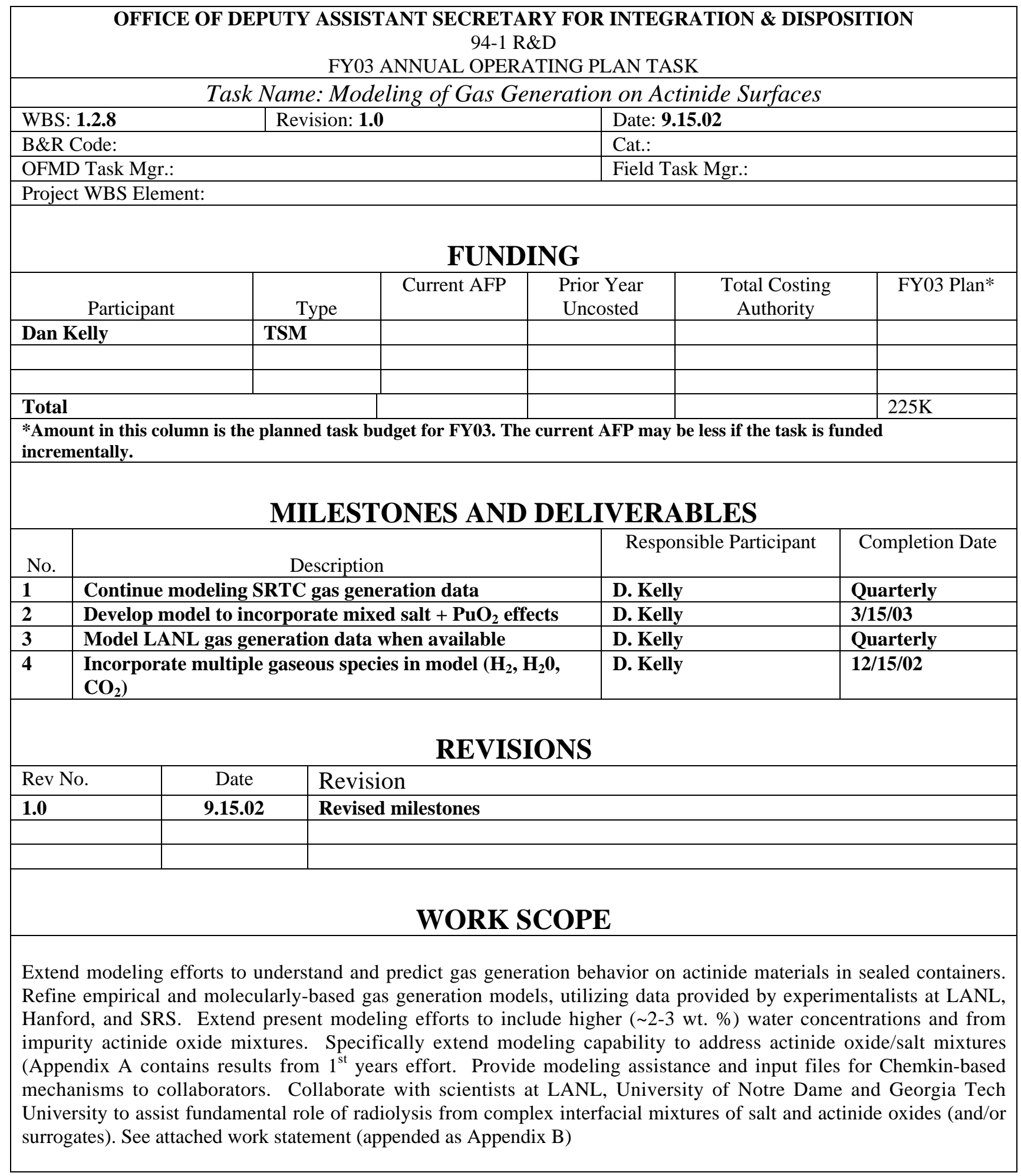


Purpose: The potential for radiolytic gas generation to pressurize transportation and storage containers is a major issue affecting Environmental Managements (USDOE-EM) ability to transport nuclear material forms for further disposition. The current ability to predict canister pressures and gas-phase compositions is restricted by a limited understanding of the fundamental processes that contribute to gas generation. Presently, simple approximations and mathematical models result in a conservatism that is unwarranted for low moisture content actinide oxide materials. This overly conservative approach to predicting gas generation results in significant increased cost for materials management of low moisture content materials. The lack of a reliable and validated modeling procedure leads to expensive testing and frequent delays. The extension of a validated computer model for gas generation beyond traditional case limits should also be critically examined for potential utility.

Scope: The scope of this project seeks to extend modeling efforts beyond the simpler cases that incorporate only gas phase reaction chemistry (CHEMKIN) or only radiation derived modeling efforts (RadCALC). The LANL model currently includes a recombination reaction wherein radiolytically produced hydrogen consumes molecular oxygen, after which the gas-phase mole fraction of hydrogen increases. For short-term storage concerns applicable to transportation scenarios, the inclusion of rates and source terms that drive gas generation are crucial for assuring the integrity of the transported packages. Experimental measurements of $\mathrm{H}_{2}+\mathrm{O}_{2}$ recombination reactions (which occur at much faster rates than radiolysis events) over pure and impure actinide oxides have unequivocally demonstrated decreases in canister pressures due to recombination. In addition, the predilection to create hazardous gas mixtures may be significantly alleviated by this important back reaction.

Approach: Our model has been developed using Chemkin software (Reaction Design). Chemkin provides a modular format where chemical equations describing gas-phase and heterogeneous reaction mechanisms are evaluated and subsequently linked to an application program. We are evaluating the chemistry occurring in sealed canisters using the Aurora application module, which simulates a constant stirred tank reactor. We run Aurora in a closed-system transient mode to determine canister pressure and gasphase mole fractions as a function of time.

Shown in Table 1 is the reaction mechanism we have developed to globally describe the pertinent reactions occurring in sealed $\mathrm{PuO}_{2}$ systems. Our current reaction mechanism of 11 equations includes radiolysis, interfacial chemical reactions, and water adsorption/desorption kinetics that contribute to gas generation. The work to date has employed clean plutonium oxide surfaces with little or no attention to the influence of impurities or reactions at container surfaces. Most of these modeling mechanisms require refinement and modification to reflect continuing experimental and theoretical investigation of the reactions they describe. As an example, the radiolytic production of hydrogen peroxide follows from experiments in liquid water and may have limited utility in low moisture content modeling scenarios. In addition, the production of hydrogen peroxide may or may not not occur on plutonium oxide surfaces. Also, we are aware that radiolysis of gas-phase constituents may lead to recombination of hydrogen and oxygen to form water, however, we believe the rate of chemical recombination (undoubtedly through a surface-mediated mechanism not detailed here) is much faster.

Table 1: Global reaction mechanism for gas generation on $\mathrm{PuO}_{2}$, where the rate coefficient for reaction, $\mathrm{k}$, is equal to $\mathrm{A} * \mathrm{~T}^{\mathrm{b}} * \exp (-$ $\mathrm{E}_{\mathrm{a}} / \mathrm{RT}$ ).

\begin{tabular}{|c|c|c|c|c|}
\hline \# & Radiolytic Reactions & $\begin{array}{l}\mathrm{A} \\
\left(\mathrm{mol} / \mathrm{sec}^{-1}\right)\end{array}$ & $\mathrm{b}$ & $\begin{array}{l}\mathrm{E}_{\mathrm{a}} \\
(\mathrm{kcal} / \mathrm{mol})\end{array}$ \\
\hline 1 & $\mathrm{H}_{2} \mathrm{O}_{(\mathrm{s})} \Rightarrow>\mathrm{H}_{2(\mathrm{~g})}+{ }_{-} \mathrm{H}_{2} \mathrm{O}_{2}$ & $8.33 \times 10^{-9}$ & 0 & 0 \\
\hline 2 & $\mathrm{PuO}(\mathrm{OH})_{2}=>\mathrm{PuO}_{2}+{ }_{-} \mathrm{H}_{2(\mathrm{~g})}+{ }_{-} \mathrm{H}_{2} \mathrm{O}_{2}$ & $8.33 \times 10^{-9}$ & 0 & 0 \\
\hline \multirow[t]{2}{*}{3} & $\mathrm{H}_{2} \mathrm{O}_{2}=>\mathrm{H}_{2} \mathrm{O}_{(\mathrm{g})}+{ }_{-} \mathrm{O}_{2(\mathrm{~g})}$ & $8.33 \times 10^{-9}$ & 0 & 0 \\
\hline & Chemical Reactions & & & \\
\hline 4 & $\mathrm{H}_{2(\mathrm{~g})}+{ }_{-} \mathrm{O}_{2(\mathrm{~g})}=>\mathrm{H}_{2} \mathrm{O}_{(\mathrm{g})}$ & $4.9 \times 10^{-4}$ & 0 & 0 \\
\hline 5 & $\mathrm{H}_{2} \mathrm{O}_{(\mathrm{g})} \Rightarrow>\mathrm{H}_{2} \mathrm{O}_{(\mathrm{s})}$ & $0.2^{(\mathrm{a})}$ & 0 & 0 \\
\hline 6 & $\mathrm{H}_{2} \mathrm{O}_{(\mathrm{s})}=>\mathrm{H}_{2} \mathrm{O}_{(\mathrm{g})}$ & $1 \times 10^{13}$ & 0 & $10.5^{(\mathrm{b})}$ \\
\hline 7 & $\mathrm{H}_{2} \mathrm{O}_{(\mathrm{s})}+\mathrm{PuO}_{2} \Rightarrow \mathrm{PuO}(\mathrm{OH})_{2}$ & $8.1 \times 10^{-4}$ & 0 & 0 \\
\hline 8 & $\mathrm{PuO}(\mathrm{OH})_{2} \Rightarrow \mathrm{PuO}_{2}+\mathrm{H}_{2} \mathrm{O}_{(\mathrm{s})}$ & $5.6 \times 10^{-1}$ & -1 & 30.7 \\
\hline
\end{tabular}




\begin{tabular}{|l|l|c|c|c|}
\hline 9 & $\mathrm{PuO}(\mathrm{OH})_{2}+{ }_{-} \mathrm{O}_{2(\mathrm{~g})}=>\mathrm{PuO}_{2}(\mathrm{OH})_{2}$ & $4.4 \times 10^{-6}$ & 0 & 9.4 \\
\hline 10 & $\mathrm{PuO}(\mathrm{OH})_{2}+\mathrm{H}_{2} \mathrm{O}_{2}=>\mathrm{PuO}_{2}(\mathrm{OH})_{2}+\mathrm{H}_{2} \mathrm{O}_{(\mathrm{s})}$ & $4.4 \times 10^{-6}$ & 0 & 9.4 \\
\hline 11 & $\mathrm{PuO}_{2}(\mathrm{OH})_{2}+\mathrm{H}_{2(\mathrm{~g})}=>\mathrm{PuO}(\mathrm{OH})_{2}+\mathrm{H}_{2} \mathrm{O}_{(\mathrm{s})}$ & $8.85 \times 10^{-10}$ & 1 & 0 \\
\hline
\end{tabular}

${ }^{\text {(a) }}$ Sticking Coefficient

${ }^{\text {(b) }} \mathrm{E}_{\mathrm{a}(300 \mathrm{~K})}=10.5, \mathrm{E}_{\mathrm{a}(525 \mathrm{~K})}=8.4$

Values in Table 1 are provided on a molar basis to evaluate the reaction rate coefficient for each reaction, given as

$$
\mathrm{k}=\mathrm{A} * \mathrm{~T}^{\mathrm{b}} * \exp \left(-\mathrm{E}_{\mathrm{a}} / \mathrm{RT}\right)
$$

Chemkin solves the set of gas-phase and heterogeneous reaction equations simultaneously and evaluates overall reaction rates according to a concentration-dependent expression. For example, the rate of surface reactions such as the radiolysis of adsorbed water to form peroxide and gas-phase hydrogen (Reaction 1) is given by

$$
\text { rate }=\mathrm{k} * \mathrm{r} * \mathrm{SA} *\left[\mathrm{H}_{2} \mathrm{O}\right]
$$

where $\mathrm{r}$ is the $\mathrm{PuO}_{2}$ surface site density $\left(\right.$ moles $\left./ \mathrm{cm}^{2}\right), \mathrm{SA}$ is the total $\mathrm{PuO}_{2}$ site area $\left(\mathrm{cm}^{2}\right)$, and $\left[\mathrm{H}_{2} \mathrm{O}\right]$ is the concentration, or fractional coverage, of adsorbed water. It should be noted that all of the above reaction equations are evaluated as pseudo-first order reactions, and the reaction rates are simply dependent on the concentration of reactant species. Empirical molar kinetic rate values for the preexponential term of Eqn. 1 are supplied for the majority of the reactions in Table 1 because experimentally derived rate coefficients for reactions similar to those found here are most often expressed as molar rates. Values to describe the adsorption/desorption behavior of water use a sticking coefficient for water adsorption, while water desorption employs a first-order frequency factor $\left(10^{13}\right.$ ) and activation energy equal to the enthalpy of desorption at the simulation temperature. We have verified that these kinetic values regarding water reliably reproduce experimentally determined pressure vs. temperature curves during the adsorption/desorption of water on $\mathrm{PuO}_{2}$ as temperature is cycled from 295 to $530 \mathrm{~K}$ and returned to $295 \mathrm{~K}$.

The preexponential term of Table 1 to describe radiolysis events (Reactions $1-3)$ has been chosen such that the initial (time $=$ 0 ) rate of hydrogen production by radiolysis of adsorbed water predicted by the Chemkin model matches that predicted by RadCalc. RadCalc predicts a molar rate of hydrogen production of approximately $7 \times 10^{-9}$ moles/sec, using an input of $5 \mathrm{~kg} \mathrm{PuO} 2(\mathrm{Pu}-239)$ and $25 \mathrm{~g}$, or $0.5 \mathrm{wt} . \%$, water. For the surface area and site density used to depict $5 \mathrm{~kg} \mathrm{PuO}_{2}$ in the Chemkin model, a rate coefficient of $8.33 \times 10^{-9}$ moles/sec gives an initial gas generation rate of $7 \times 10^{-9}$ moles $\mathrm{H}_{2} / \mathrm{sec}$ arising from the radiolysis of $25 \mathrm{~g}$ of adsorbed water. We note that RadCalc does not conserve mass and hence predicts a constant rate of $\mathrm{H}_{2}$ production (for constant loadings of PuO $\mathrm{O}_{2}$ and $\mathrm{H}_{2} \mathrm{O}$ ), no matter what fraction of the initially loaded water is extant in the system over time. Chemkin, however, accounts for the fact that as radiolysis of water proceeds, the rate of hydrogen production must decrease because the concentration of water is diminishing. As a first approximation to describing the overall behavior of the gas generation system, we have chosen identical rate coefficients for all radiolytic reactions.

Other pertinent simulation parameters and methodology are as follows. DOE Standard 3013 dictates that the maximum loading of actinide oxide material in sealed canisters is $5 \mathrm{~kg}$, and the maximum allowable loading of water is $0.5 \mathrm{wt}$. \%, or $25 \mathrm{~g} \mathrm{H}_{2} \mathrm{O}$. We consider the canister to have the dimensions of an "inner" can, following examples portrayed in the 3013 standard. The volume of the can is $2266 \mathrm{ml}$. In all simulations the canister is portrayed to contain $5 \mathrm{~kg} \mathrm{PuO}_{2}$ with a density of $11.5 \mathrm{~g} / \mathrm{ml}$, and hence the free volume of the can is $1831 \mathrm{ml}$. A surface area of $5 \mathrm{~m}^{2} / \mathrm{g}$ is assumed for the $\mathrm{PuO}_{2}$. Assuming a site area for water adsorption of 12.5 $\AA^{2}$, we note that 0.5 wt. $\% \mathrm{H}_{2} \mathrm{O}$ corresponds to a surface coverage of 4.2 monolayers (ML) of $\mathrm{H}_{2} \mathrm{O}$ on $5 \mathrm{~kg}$ of PuO . In all cases the canister is packaged with dry air $\left(21 \% \mathrm{O}_{2}, 79 \% \mathrm{~N}_{2}\right)$ at $300 \mathrm{~K}$ and $1 \mathrm{~atm}$. Simulation times presented here are 3 years, although longer-time simulations are easily carried out. Simulations at temperatures higher than $300 \mathrm{~K}$ are carried out by ramping the system to the desired temperature over a short time period ( hours) within the 3-year simulation time frame. The change in pressure accompanying this temperature change is accounted for by the ideal gas law, i.e., a simulation at $525 \mathrm{~K}$ has an effective initial pressure of $(525 \mathrm{~K} / 300 \mathrm{~K}) * 1 \mathrm{~atm} .=1.75 \mathrm{~atm}$., as it should since it is packaged at $300 \mathrm{~K}$ and $1 \mathrm{~atm}$. 
The Chemkin model we have developed includes the ability to simulate chemical reaction rates that are dependent on water loading. Since relatively small mass loadings of water $(\sim 0.5 \mathrm{wt} \%)$ correspond to multiple layers of adsorbed water on $\mathrm{PuO}_{2}$, the ability to incorporate concentration-dependent water reactions into the model may be paramount to properly describing the overall system behavior. Specifically, experimental evidence suggests that the radiolysis rate coefficients for adsorbed water are dependent on the proximity of the water to the radiolytic source. Hence, proper description of the behavior for a $0.5 \mathrm{wt} \%$ water loading may require the rate coefficient of water radiolysis of the fourth ML to be substantially different than that of first ML water directly bound to the $\mathrm{PuO}_{2}$ surface. We note that only reactions involving the radiolysis of water (Reaction 1), and the radiolysis of subsequently formed peroxides (Reaction 3), are affected by this layering approach. Reactions involving $\mathrm{PuO}_{2}$ moieties and water occur only within the first water ML and hence their rate expressions would not be expected to be dependent on the amount of water present. Also, we find that Reactions 5 and 6 describing water adsorption/desorption are adequate to reproduce experimental results on $\mathrm{PuO}_{2}$ surfaces for water loadings corresponding to at least $10 \mathrm{ML}$, i.e., water adsorption/desorption does not require concentration dependence. This methodology of correlating water mass loading to a layered simulation structure, where the kinetic parameters describing water reactions are layer-dependent, is referred to several times below and the layer-dependent radiolysis rates are delineated where necessary. 


\begin{tabular}{|c|c|}
\hline \multicolumn{2}{|c|}{$\begin{array}{c}\text { OFFICE OF DEPUTY ASSISTANT SECRETARY FOR INTEGRATION \& } \\
\text { DISPOSITION } \\
\text { 94-1 R\&D Work Package } \\
\text { FY03 WORK PACKAGE/ANNUAL OPERATING PLAN TASK }\end{array}$} \\
\hline \multicolumn{2}{|c|}{ Task Name: SRTC Experimental Gas Generation Studies } \\
\hline \begin{tabular}{|l|l|} 
& Revision: 0 \\
\end{tabular} & Date: November 20, 2002 \\
\hline B\&R Code: EW02A301D & Cat.: \\
\hline OFMD Task Mgr.: & \\
\hline
\end{tabular}

\begin{tabular}{|l|l|l|l|l|l|}
\hline \multicolumn{6}{|c|}{ FUNDING } \\
\hline \multicolumn{1}{|c|}{ Participant } & Type & Current AFP & $\begin{array}{c}\text { Prior Year } \\
\text { Uncosted }\end{array}$ & $\begin{array}{c}\text { Total Costing } \\
\text { Authority }\end{array}$ & FY03 Plan* \\
\hline Ron Livingston & & & & & \\
\hline & & & & & \\
\hline Total & & & & & $\$ 400 \mathrm{~K}$ \\
\hline
\end{tabular}

\begin{tabular}{|l|l|l|l|}
\hline \multicolumn{4}{|c|}{ MILESTONES AND DELIVERABLES } \\
\hline No. & \multicolumn{1}{|c|}{ Description } & $\begin{array}{c}\text { Responsible } \\
\text { Participant }\end{array}$ & Completion Date \\
\hline 1 & Updates of gas generation rate/pressure results & Livingston & Quarterly \\
\hline 2 & Improved small-scale test apparatus implemented & Livingston & March 03 \\
\hline 3 & TGA/BET analysis of PuO2 test materials & Livingston & June 03 \\
\hline 4 & Report on steady state H2 pressure for 3013 storage & Livingston & September 03 \\
\hline
\end{tabular}

\begin{tabular}{|l|c|l|}
\hline \multicolumn{2}{|c|}{ REVISIONS } \\
\hline Rev No. & Date & Revision \\
\hline Draft 0 & $\mathbf{1 1 / 2 0 / 2 0 0 2}$ & \\
\hline & & \\
\hline & & \\
\hline
\end{tabular}

\section{WORK SCOPE}

SRTC will provide experimental gas generation support for the 94-1 Program. This effort will use small-scale gas generation test apparatus to evaluate the impacts of 3013 storage conditions. Results of these tests will support LANL efforts to develop molecularly based gas generation models. These small-scale tests will address factors that impact hydrogen generation rates, gas composition, and steady-state pressures. Objectives for FY03 include:

- Support installation of TGA \& BET instruments to improve test materials characterization

- Improve gas generation test apparatus for small gas samples and elevated temperature tests

- Continue measurements of gas generation rates for pure \& impure oxides to support program needs

- Investigate factors contributing to steady state $\mathrm{H} 2$ pressures in 3013 contents

- Support emerging program needs related to gas generation and 3013 storage

- Add capability for small corrosion specimens in test apparatus

- Continue participation in MIS \& JOWOG efforts

- Present research findings in technical reports and conferences

Purpose: 
The Savannah River Technology Center's objectives are designed to provide experimental measurements of the gas generation phenomena relevant to storage of plutonium-bearing materials per the DOE-STD-3013.

Scope:

This project is a continuation from FY02 efforts that measured the gas generation rates associated with moisture adsorbed on pure plutonium dioxide as a function of calcination temperature. This effort will be expanded in FY03 to evaluate the impact of both adsorbed moisture and impurities of concern for 3013 storage on gas generation. Additional efforts will focus on examining the mechanisms that limit hydrogen pressure during storage.

Approach:

SRTC will use small-scale test apparatus to measure the gas pressures and compositions over well-defined, plutonium-bearing materials. These measurements will complement the work at LANL on MIS samples. The small-scale experiments are designed to provide test data that support gas generation modeling and to provide empirical results that help resolve emerging questions. The focus of SRTC gas generation measurements will change from pure to impure plutonium materials and increase emphasis on concerns relevant to surveillance of 3013 containers.

Test results in FY02 demonstrated the potential importance of water layers on gas generation rate. This observation will be better defined with the addition of TGA-MS moisture analysis and BET surface area analysis capabilities. In general the ability of SRTC to help resolve gas generation questions will be greatly enhanced by installation of TGA-MS and BET instruments.

With our current small-scale test apparatus we are limited to analysis of a single gas sample at the conclusion of a test. By modifying the test apparatus and interfacing a micro gas chromatograph, numerous experimental limitations will be overcome at SRTC. The advantages of this modification include the ability to evaluate potential steady state gas compositions, measure gas generation rates at elevated temperatures, and scale tests with varied headspace-to-oxide ratios.

Gas generation studies with impure plutonium-bearing oxides during FY03 will include tests of moisture adsorbed in various forms. For example, tests will be conducted with tightly bound (chemisorbed) and loosely bound (physisorbed) water on metal oxides, in addition to hydroxide and hydrate forms (e.g. $\mathrm{Ca}(\mathrm{OH})_{2}, \mathrm{CaCl}_{2} \cdot \mathrm{xH}_{2} \mathrm{O}$ ). Other impurities are being defined as part of a test plan, but are expected to include carbonates and typical impurities observed in MIS samples with the potential to adsorb water or decompose in the storage environment.

Additional tests will examine the factors that impact an observed steady-state hydrogen pressure. The ability to define these conditions may support eventual lowering of the pressure predicted by the DOE-STD-3013 and subsequently reduce the risk associated with storage and opening of the 3013 container.

The flexibility associated with the SRTC test configuration will support inclusion of corrosion test samples. These may be used to measure short-term changes in the metal surface related to contact with impure plutonium oxides.

The findings of these experimental efforts will be presented regularly at MIS and related meetings. Peer review of the efforts is expected to continue via presentation and publication of the experimental results. These interactions are anticipated to allow SRTC to respond to emerging 94-1 program needs that are related to gas generation and 3013 storage. 


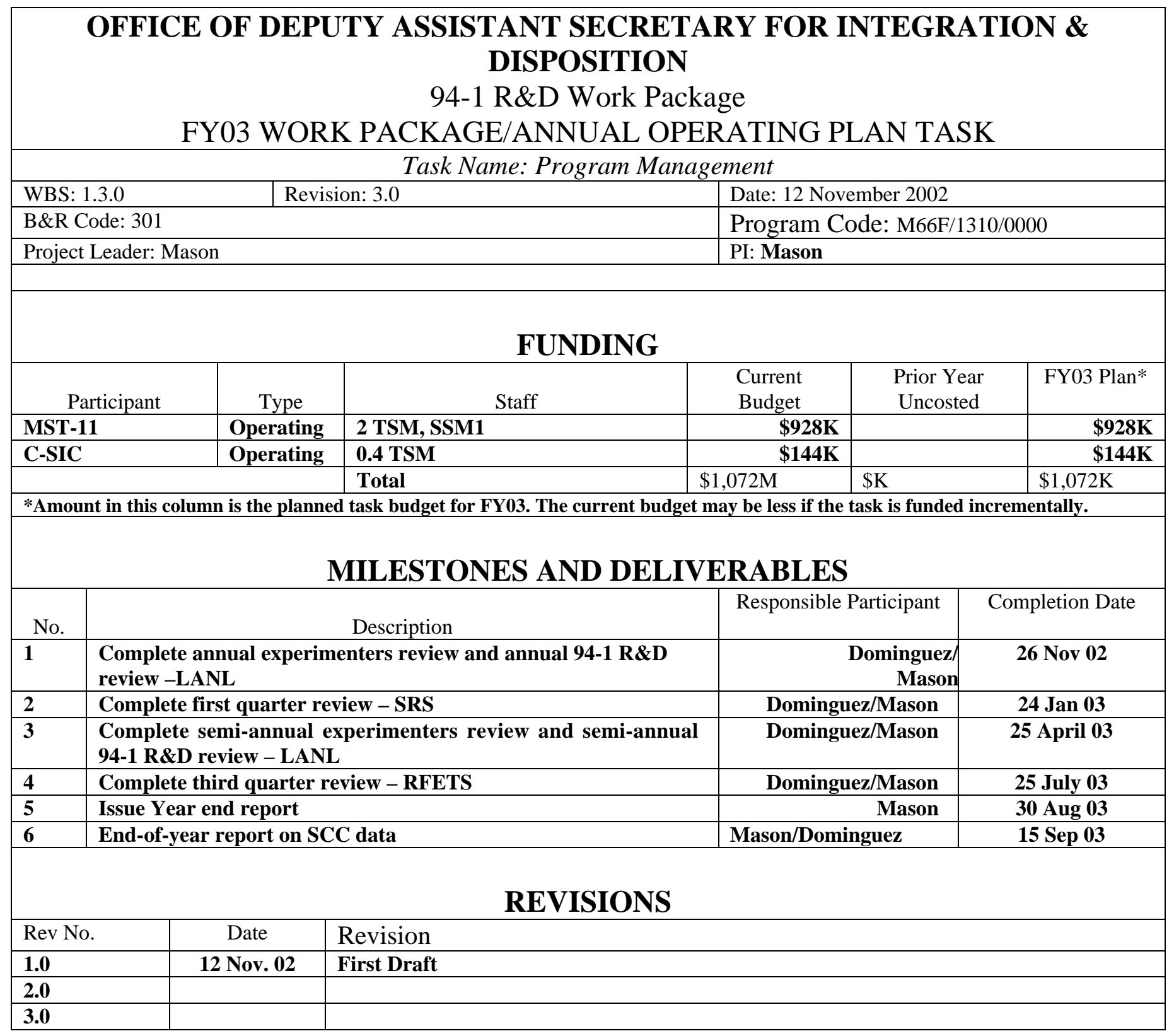




\section{WORK SCOPE}

Scope:

Perform program coordination, integration, oversight, reporting, and reviews for the overall 94-1 R\&D Program, as well as for the specific work that is performed in the Material Identification; Stabilization Technology Development; Surveillance and Monitoring Technology; and Core Technology. Also included within this WBS is management of the DOE-STD-3013, which includes periodic review and update of the standard as a result of new information that is obtained through continuing research and analysis of the standard's technical basis.

- $\quad$ Provide technical review and evaluations to support the biannual review of the DO)-STD-3013. (NMT-11 and CSIC)

- $\quad$ Provide support for all activities in the 94-1 R\&D program 
Signatures:

NMT-11 Group Leader

C-SIC Group Leader

Principal Investigator

Project Leader

Program Manager
Date

Date

Date

Date

Date 
This report has been reproduced directly from the best available copy. It is available electronically on the Web (http://www.doe.gov/bridge).

Copies are available for sale to U.S. Department of Energy employees and contractors from:

Office of Scientific and Technical Information P.O. Box 62

Oak Ridge, TN 37831

(865) 576-8401

Copies are available for sale to the public from: National Technical Information Service

U.S. Department of Commerce

5285 Port Royal Road

Springfield, VA 22616

(800) 553-6847 
